\title{
Preparation and Properties of C/SiC Composites Reinforced by High Thermal Conductivity Graphite Films
}

\section{Jiajia Zhao}

Beijing University of Chemical Technology

\section{Rong Cai}

Beijing University of Chemical Technology zhaokun Ma ( $\square$ mazk@mail.buct.edu.cn ) Beijing University of Chemical Technology

Kaixuan Zhang

Changzhou Institute of Advanced Materials

\section{Hengliang Liang}

AVIC Composite Corporation Ltd

\section{Haipeng Qiu}

AVIC Composite Corporation Ltd

\section{Shanhua Liu}

AVIC Composite Corporation Ltd

weijie xie

AVIC Composite Corporation Ltd

\section{Research Article}

Keywords: SiC composites, carbon fibers, high thermal conductivity graphite films, ablation resistance

Posted Date: December 1st, 2020

DOI: https://doi.org/10.21203/rs.3.rs-115405/v1

License: (c) (1) This work is licensed under a Creative Commons Attribution 4.0 International License. Read Full License 


\title{
Preparation and properties of $\mathrm{C} / \mathrm{SiC}$ Composites reinforced by high thermal conductivity graphite films
}

\author{
Jiajia Zhao ${ }^{1}$, Rong $\mathrm{Cai}^{1}$, Zhaokun $\mathrm{Ma}^{1,{ }^{*}}$, Kaixuan Zhang ${ }^{2}$, Hengliang Liang ${ }^{3,4}$, Haipeng Qiu ${ }^{3,4}$, \\ Shanhua Liu ${ }^{3,4}$, WeijieXie ${ }^{3,4}$.
}

${ }^{1}$ Beijing Key Laboratory Electrochemical Process and Technology for Materials, State Key Laboratory of Chemical Resource Engineering, Beijing University of Chemical Technology, Beijing 100029, P.R. China

${ }^{2}$ Changzhou Institute of Advanced Materials, Beijing University of Chemical Technology, Changzhou 213164, P.R. China

${ }^{3}$ AVIC Composite Technology Center, Beijing 101300, P.R. China

${ }^{4}$ Technical Development Department, AVIC Composite Corporation LTD, Beijing 101300, P.R. China

\begin{abstract}
Ablation resistance as one important factor affecting the service life of $\mathrm{SiC}$ ceramic matrix composites that is highly valued in aerospace science and technology. In this study, high thermal conductivity (HTC) graphite films and carbon fibers reinforced C/SiC composites simultaneously, fabricating by precursor infiltration and pyrolysis (PIP) technology, to improve the ablation resistance of $\mathrm{C} / \mathrm{SiC}$ composites. Three $\mathrm{C} / \mathrm{SiC}$ composites were prepared from different quantity ratios of 2D fiber cloth to HTC graphite film with values of 1:0, 1:1, and 1:10. The microstructure,
\end{abstract}

\footnotetext{
Jiajia Zhao and Rong Cai have contributed equally to this work.

* Corresponding author.

E-mail address: mazk@mail.buct.edu.cn (Z.Ma)
} 
mechanical properties, thermal conductivity and ablation performance of $\mathrm{C} / \mathrm{SiC}$ composites after plasma ablation test at $1500^{\circ} \mathrm{C}$ for $600 \mathrm{~s}$ were investigated. The results showed that with the increase of graphite films' contents, the thermal conductivity of composites was increased from $9.78 \mathrm{~W} /(\mathrm{m} \cdot \mathrm{K})$ to $333.34 \mathrm{~W} /(\mathrm{m} \cdot \mathrm{K})$. Additionally, the mass loss rate reduced from 1.18 to $0.74 \mathrm{mg} / \mathrm{s}$ and the linear ablation rate reduced from 0.64 to $0.18 \mathrm{~mm} / \mathrm{s}$, indicating that the addition of graphite films could effectively improve the ablation resistance of $\mathrm{C} / \mathrm{SiC}$ composites.

Keywords: $\mathrm{SiC}$ composites; carbon fibers; high thermal conductivity graphite films; ablation resistance

\section{Introduction}

$\mathrm{SiC}$ ceramic matrix reinforced by continuous carbon fibers $(\mathrm{C} / \mathrm{SiC})$ composites behave excellent properties as low density, high thermal shock resistance, good ablation resistance as well as cost effective production, which are widely used in space propulsion systems as the advanced friction materials[1-4]. Meanwhile, the oxidation resistance of $\mathrm{C} / \mathrm{SiC}$ composites showed good oxidation resistance and high-temperature performance, which is better than $\mathrm{C} / \mathrm{C}$ and $\mathrm{SiC} / \mathrm{SiC}$ composites.

Ceramic matrix composites, reinforced by carbon fibers and matrices of silicon carbide (such as $\mathrm{C} / \mathrm{C}-\mathrm{SiC}, \mathrm{C} / \mathrm{SiC}$ ) have drawn great attention for their good thermal protection properties [5]. Generally, the silica protective layer formed on the surface of the composites below $1700^{\circ} \mathrm{C}$ in the static oxidation environment, yet which would be peeled off under the heat flux and high-pressure airflow environment[6]. The peeling of silica layers seriously affects the performance of $\mathrm{C} / \mathrm{SiC}$ composites, which could not meet long-term and reusable requirements for aircrafts. Therefore, it is essential to enhance the ablation resistance for $\mathrm{C} / \mathrm{SiC}$ composites[7-9]. In recent years, many 
investigations have been performed to improve the ablation resistance of $\mathrm{C}_{\mathrm{f}} / \mathrm{SiC}$ composites such as introducing ultra-high temperature ceramics (UHTCs, e.g., $\mathrm{ZrB}_{2}, \mathrm{ZrC}, \mathrm{TaC}$, and $\mathrm{HfC}$ ) into $\mathrm{SiC}$ matrix because of the UHTCs' extremely high melting point temperature, good thermal shock resistance and high-temperature strength[1, 3, 10-12]. Zhang et al.[5] and Zhang et al.[13] investigated microstructural features and mechanical properties of $\mathrm{ZrB}_{2}-\mathrm{SiC}-\mathrm{ZrC}$ composites which is fabricated by hot pressing and reactive hot pressing. Tang et al.[1] prepared a $\mathrm{C}_{\mathrm{f}} / \mathrm{ZrB}_{2}-\mathrm{SiC}$ composite with good oxidation and ablation resistance by chemical vapor infiltration (CVI), through infiltrating $\mathrm{SiC}$ matrix into carbon fiber- $\mathrm{ZrB}_{2}$ powder preform. NASA discovered that the performance of $\mathrm{ZrB}_{2} / \mathrm{ZrC} / \mathrm{SiC}$ composites is better than $\mathrm{ZrB}_{2} / \mathrm{SiC}$ or $\mathrm{HfB}_{2} / \mathrm{SiC}$ composites[14]. Wu et al. reported a $\mathrm{C}_{f} / \mathrm{C}-\mathrm{ZrC}-\mathrm{SiC}$ composite prepared by PIP process using a hybrid precursor containing polycarbosilane and zirconium-containing polymeric precursor[3]. The above studies all showed that the ablation resistance of $\mathrm{C}_{\mathrm{f}} / \mathrm{SiC}$-UHTC composites could be improved by the addition of UHTCs.

In addition, as the speed of aircraft becomes faster and faster, the leading edge structure of the aircraft is often designed to be very sharp (the leading edge radius is even in millimeters) to achieve high lift and low resistance, which also caused extremely serious the local aerodynamic heating problem. Coupled with the concept of reusable launch vehicle, a certain thermal protection structure is required for reusability and reduce preparation time. Therefore, "Dredging" thermal protection becomes a relatively efficient way of thermal protection[15]. "Dredging" thermal protection is using materials or structures with high thermal conductivity to quickly direct high aerodynamic heat flow near the material stagnation point to the low heat flow region at the rear of the structure, thereby reducing the temperature at the stagnation point, the structural temperature gradient and thermal 
stress $[16,17]$. Therefore, for meeting the requirements of aerospace science and technology, $\mathrm{C} / \mathrm{SiC}$ composites should have both good ablation resistance and high thermal conductivity, thereby expanding the application range and service life of the material[18]. However, current $\mathrm{C} / \mathrm{SiC}$ composites are limited by the low thermal conductivity of carbon fibers, which only reaches $10 \sim 30 \mathrm{~W} /(\mathrm{m} \cdot \mathrm{K})$. Therefore, it is urgent to prepare composites with higher thermal conductivity so as to improve their ablation performance.

In this study, a new HTC graphite film was introduced into the $\mathrm{C} / \mathrm{SiC}$ material system. The effects of different content of graphite film on the density, microstructure, mechanical properties and thermal conductivity of $\mathrm{C} / \mathrm{SiC}$ composites were investigated. The ablation performance of the new $\mathrm{HTC} \mathrm{C} / \mathrm{SiC}$ composites prepared at $1500^{\circ} \mathrm{C}$ for $600 \mathrm{~s}$ was performed by plasma spray flame test and the ablation mechanism was studied. Also the relationship between the ablation resistance and thermal conductivity of $\mathrm{C} / \mathrm{SiC}$ composites with different content of graphite film was investigated.

\section{Experiment}

\subsection{Preparation of $\mathrm{C} / \mathrm{SiC}$ composites reinforced by HTC graphite films}

The $\mathrm{C} / \mathrm{SiC}$ composites were prepared by impregnated Polycarbosilane (PCS), which was used as precursor of matrix, combining the HTC graphite films and carbon cloth as reinforcement. The properties of HTC graphite films are shown in Table $\mathbf{1 .}$

Table 1 The characteristics of HTC graphite film

\begin{tabular}{ccccc}
\hline $\begin{array}{c}\text { Thermal film } \\
\text { thickness }(\mu \mathrm{m})\end{array}$ & $\begin{array}{c}\text { Thickness } \\
\text { tolerance } \\
(\mu \mathrm{m})\end{array}$ & $\begin{array}{c}\text { Thermal } \\
\text { conductivity } \\
(\mathrm{W} / \mathrm{m} \cdot \mathrm{K})\end{array}$ & $\begin{array}{c}\text { Thermal } \\
\text { diffusivity } \\
\left(\mathrm{cm}^{2} / \mathrm{s}\right)\end{array}$ & Density $\left(\mathrm{g} / \mathrm{cm}^{3}\right)$ \\
\hline & & $>1100$ & $>7$ & $1.60-1.80$ \\
\hline
\end{tabular}


The processing conditions of $\mathrm{HTC} \mathrm{C} / \mathrm{SiC}$ composites are as follows. First, the T300 fibers (Japan Toray Company) were woven into the $2 \mathrm{D}$ fiber cloth as a reinforcement for the $\mathrm{C} / \mathrm{SiC}$ composites. 2D fiber cloth and HTC graphite film were respectively prepared into preforms at quantity ratio of 1:0, 1:1, and 1:10. Second, adding a small amount of Pyrocarbon (PyC) to the treated preform by pyrolysis natural gas for $10 \mathrm{~h}$ at $1000^{\circ} \mathrm{C}$ in an isothermal CVI apparatus. In the third stage, using PCS as the matrix precursor, impregnating for $24 \mathrm{~h}$ under vacuum, the impregnated pre-formed body was placed in a graphite mold. Then the mold was placed in a hot press molding machine, heated to $200^{\circ} \mathrm{C}$ for hot press molding, and constant pressure heat preservation for $0.5 \mathrm{~h}$ to obtain $2 \mathrm{D} \mathrm{C} / \mathrm{SiC}$ composites. The size of the green body is about $40 \mathrm{~mm} \times 120 \mathrm{~mm} \times 3 \mathrm{~mm}$. The green body samples were subsequently subjected to high-temperature graphitization heat treatment $\left(1600{ }^{\circ} \mathrm{C}\right)$. Finally, infiltration and pyrolysis are repeated, and the maximum heat treatment temperature is $1200{ }^{\circ} \mathrm{C}$. The final obtained $\mathrm{C} / \mathrm{SiC}$ composites are marked as CS-1, CS-2 and CS-3. The process flow is shown in Fig. 1.

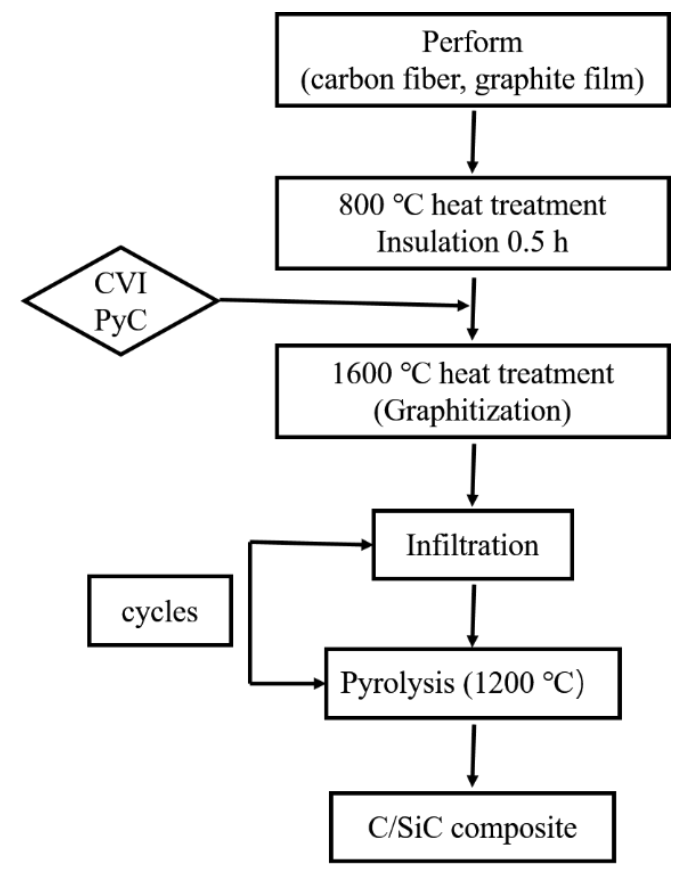

Fig. 1 Process flow chart of $\mathrm{HTC} \mathrm{C/SiC} \mathrm{composites}$ 


\subsection{Characterization}

The ceramic powder density, apparent densities and open porosities of the $\mathrm{C} / \mathrm{SiC}$ composites were measured by Archimedes' method. The electronic universal testing machine (CMT 5304, Suns Co., China) was employed to perform three-point bending tests on the samples on size of $36 \mathrm{~mm} \times$ $4 \mathrm{~mm} \times 3 \mathrm{~mm}$. The test span and load speed are $30 \mathrm{~mm}$ and $5 \mathrm{~mm} / \mathrm{min}$, respectively.

The thermal conductivities $(\lambda)$ of $\mathrm{C} / \mathrm{SiC}$ composites along the graphite films were calculated from their thermal diffusivities $(\alpha)$, densities $(\rho)$ and specific heat capacities $(\mathrm{Cp})$ according to the equation:

$$
\lambda=\alpha \times \rho \times \mathrm{C}_{\rho}
$$

A laser flash apparatus (LFA447/2-2Insb Nano Flas, Germany) was used to measure $\alpha$ at room temperature and the samples were perpendicular or parallel to the two directions of the $\mathrm{C} / \mathrm{SiC}$ composite friction surface. The measured size of sample is $10 \mathrm{~mm} \times 10 \mathrm{~mm} \times 3 \mathrm{~mm}$ and corresponding schematic diagram for mechanism of the laser flash method is shown in Fig. 2[19].

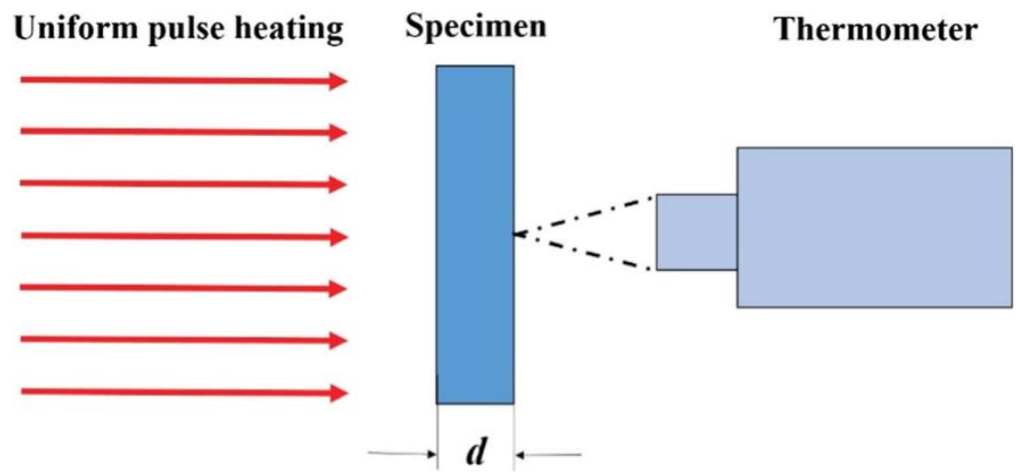

Fig. 2 The mechanism of the laser flash method[19]

The ablation test was carried out in plasma art-jet flame. During the test, the specimen with a size of $30 \mathrm{~mm} \times 30 \mathrm{~mm} \times 4 \mathrm{~mm}$ was vertically exposed to the flame for $600 \mathrm{~s}$ when the surface temperature of the composite reached up to $1800^{\circ} \mathrm{C}$. The linear and mass ablation rates of specimens were calculated according to formulas: 


$$
\begin{aligned}
& R_{d}=\frac{\left(d_{1}-d_{2}\right)}{t} \\
& R_{m}=\frac{\left(m_{1}-m_{2}\right)}{t}
\end{aligned}
$$

Where $R_{d}$ is the linear ablation rate, $d_{1}$ and $d_{2}$ is the thickness of the center region of the samples before and after ablation, respectively. $R_{m}$ is the mass loss rate, $m_{1}$ and $m_{2}$ is the mass of samples before and after ablation, and $t$ represents the ablation time. The final linear and mass ablation rates of the composite are the average ablation rate of three samples.

Scanning electron microscopy (SEM, S-4800, Hitachi, Japan) was employed to analyze the microstructure of materials. And Phase analysis was conducted by X-ray diffraction (XRD), via a computer controlled diffractometer (Rigaku D/max-2400, Tokyo, Japan) with Cu Ka radiation at 40 $\mathrm{kV}$ and $100 \mathrm{~mA}[20]$.

\section{Results and discussion}

\subsection{Microstructure of the $\mathrm{C} / \mathrm{SiC}$ composites}

Based on the quantity ratio of carbon fiber cloth to graphite film, the volume ratios of carbon fiber cloth, graphite film and SiC ceramic matrix of CS-1, CS-2 and CS-3 are listed in Table 2, also the density and open porosity. We found that the bulk density was decreased with the content of graphite films increasing, but the open porosity was increased. The polished cross-sectional microstructures of materials are shown in Fig. 3. In CS-1 (Fig. 3a), the fiber tows are tightly combined with the ceramic matrix and are homogenously distributed. However, with the graphite films content increasing, pores gradually appeared in the composites, especially in CS-3 (Fig. 3c), the pores between fiber cloth and graphite film are larger, which weakened the mechanical properties of $\mathrm{C} / \mathrm{SiC}$ composites. In addition, the surface of the graphite film is too smooth (as shown in Fig. 3d) that the bond with $\mathrm{SiC}$ matrix is not well, which is corresponding to the result that the 
porosity of the composites increase with the increase in the content of graphite film and the decrease in the density.

Table 2 Physical parameters of sample prepared from different graphite film and carbon fiber cloth volume ratios

\begin{tabular}{cccccc}
\hline sample & $\begin{array}{c}\text { Bulk density } \\
\left(\mathrm{g} / \mathrm{cm}^{3}\right)\end{array}$ & $\begin{array}{c}\text { Open porosity } \\
(\%)\end{array}$ & Fiber Volume & Graphite film Volume & Matrix volume \\
\hline CS-1 & 1.91 & 10.2 & 40 & fraction $(\%)$ & fraction $(\%)$ \\
CS-2 & 1.81 & 10.9 & 38 & 2 & 49.8 \\
CS-3 & 1.76 & 12.4 & 21 & 19 & 49.1 \\
\hline
\end{tabular}
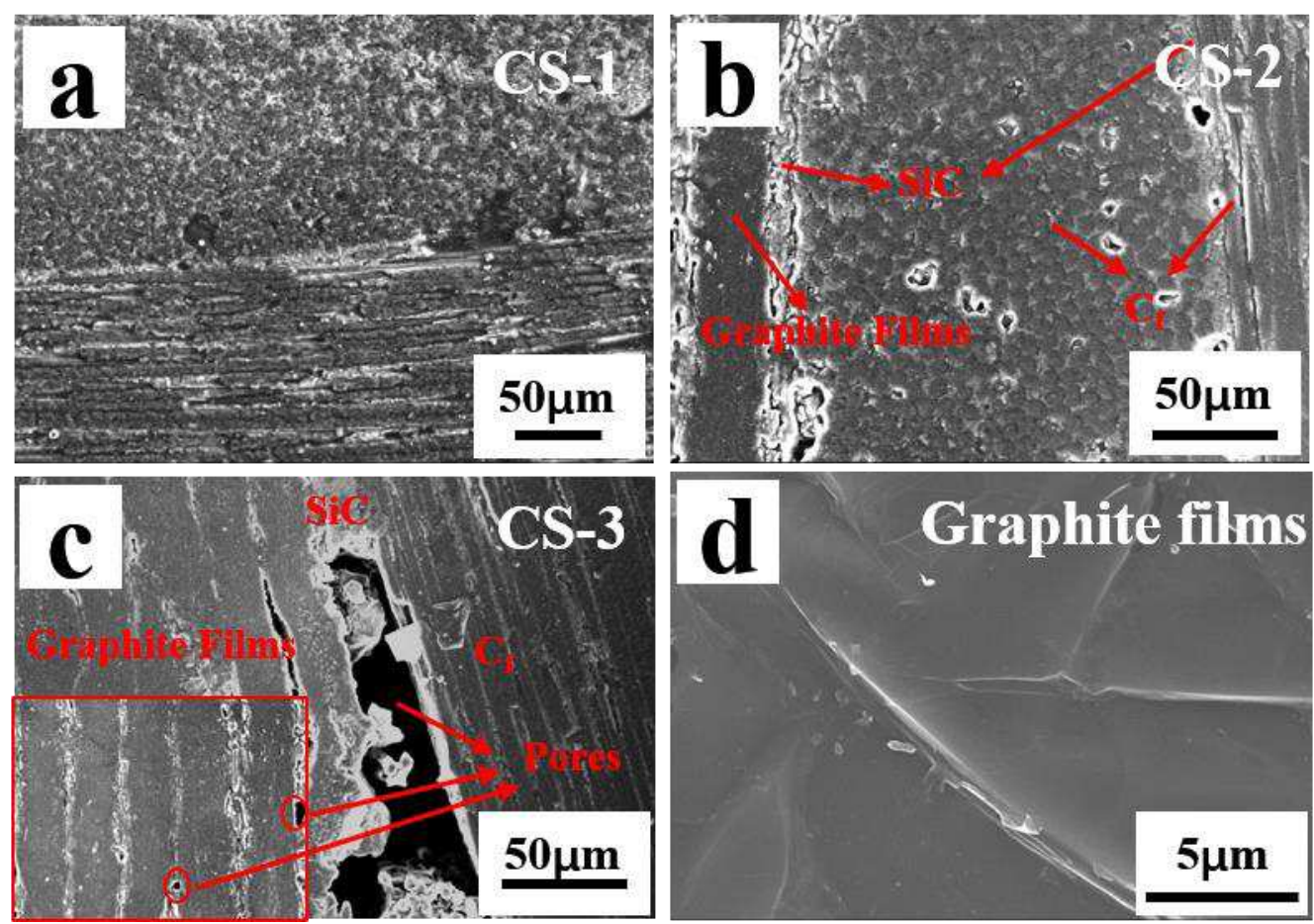

Fig. 3 SEM images of polished cross-section microstructure for (a) CS-1, (b) CS-2, (c) CS-3, and

(d) Graphite films.

The XRD patterns of the three composites are shown in Fig. 4. Compared with CS-1 which 
only contains amorphous $\mathrm{C}$ and $\mathrm{SiC}$ phase, the XRD patterns of CS-2 and CS-3 exist graphitized carbon phase located at $2 \Theta=26.4^{\circ}$ and $2 \Theta=54.5^{\circ}$, corresponding to the (002) and (004) crystal planes of graphite. The diffraction peak of graphitized carbon in the CS-3 is sharper than that of the CS-2 because the graphite film is subjected to high temperature graphitization. Thus, the more graphite film added in the $\mathrm{C} / \mathrm{SiC}$ composite, the stronger crystallization peak of the $\mathrm{C}$ phase.

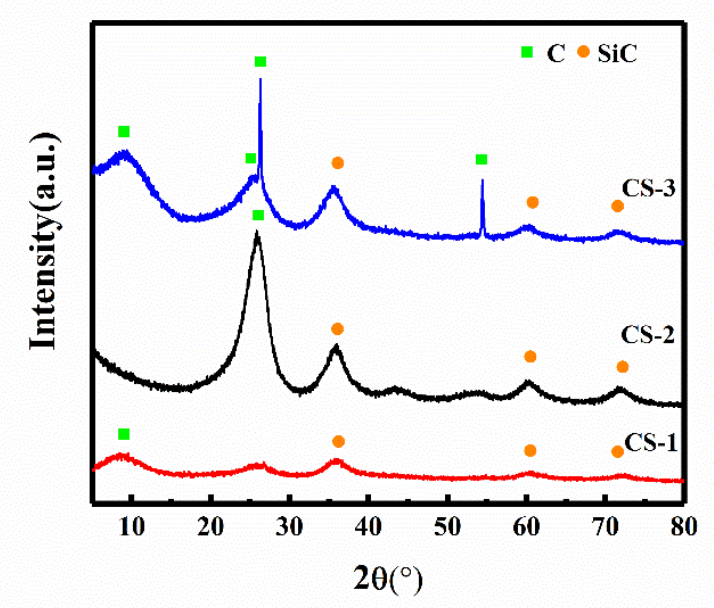

Fig. 4 XRD analysis of three materials.

\subsection{Mechanical performance of composites}

Table 3 demonstrates the results of mechanical test of three materials. It can be observed that the flexural strength and elastic modulus of the composites decreased with the increasing of graphite films content. The flexural strength of the CS-1 is $337.2 \mathrm{MPa}$, yet the CS-2 has a bending strength of 41.3 MPa, which is reduced by an order of magnitude. When the graphite film in the composite further increased, the mechanical properties are further decreased, which indicated that the addition of graphite films into $\mathrm{C} / \mathrm{SiC}$ composites has some negative effect on the flexural strength for these composites. The flexural strength $\sigma_{\mathrm{TS}}$ of composites is given by the following equation[21]:

$$
\sigma_{T S}=V_{L} \sigma_{\text {tow }}
$$

Wherein, $\sigma_{\text {tow }}$ is the strength of fiber bundle; $\mathrm{V}_{\mathrm{L}}$ is the volume fraction of carbon fiber along 
the loading direction. For the three composites in this study, with the graphite films content increasing, the $\mathrm{V}_{\mathrm{L}}$ decreased. Therefore, the flexural strength of $\mathrm{C} / \mathrm{SiC}$ composites decreased with the graphite films content increasing in composites.

In addition, as mentioned above, the density of the composites decreased as the graphite film content increased. The effect of density on flexural strength is essentially the magnitude of the effective bearing area of the composite perpendicular to the direction of force. The lower density of composites, the effective bearing area is smaller and the strength is lower. And, it obeys the relationship between fracture strength and porosity (Eq. (5)), which could be understood that the fracture strength is strongly influenced by porosity with exponential function[22]. Therefore, the flexural strength of CS-1 composite is higher than the others.

$$
\sigma_{\mathrm{f}}=\sigma_{0} \mathrm{e}^{-\mathrm{np}}
$$

Table 3 Flexural strength and elastic modulus of three materials

\begin{tabular}{ccc}
\hline Sample & Flexural Strengths (MPa) & Elastic modulus (GPa) \\
\hline CS-1 & $337.2 \pm 20.9$ & $51.9 \pm 6.1$ \\
CS-2 & $41.3 \pm 9.3$ & $5.2 \pm 2.3$ \\
CS-3 & $20.6 \pm 5.7$ & $3.7 \pm 1.2$ \\
\hline
\end{tabular}

Fig. 5a showed the flexural stress-displacement curves of the composites. All three materials exhibited toughness fracture instead of brittleness fracture. The composites present a slight deviation from linearity before reaching the maximum value for the stress, and then the stress gradually decreased with the displacement increasing, which indicates a damage-tolerant fracture behavior. In addition, we found that as the content of graphite films increases in composites, the tail of the curve is longer, which indicates composites are less likely to break completely. Also the surface of graphite 
film is too smooth (as show in Fig. 3d), which could not be well combined with the substrate, and the flexural strength between graphite film and carbon fibers is weak, leading to that load cannot effectively transmit between the substrate and fibers, and the fiber reinforcement effect is not well[10]. To clarify the reduction of the strength, SEM was employed to observe the cross section of the composites after the flexural strength test (Fig. 5(b-d)). It can be seen that all the composites showed typical non-brittle fracture behavior and there are fiber pullouts accompanying the fracture process. This result may owe to the increase of the content of graphite film, causing the degree of bonding between the fiber bundles become poor and the connection is weak. In general, the weak interfacial bonding could enhance strength and roughness. However, the surface of graphite film is very smooth, during the fracture process, the delamination of the graphite film and fibers is more serious, which leads to a decrease in strength. Meanwhile, because of the good toughness of the graphite film, it is difficult for it to be broken with the pressure increasing, so the tail is usually long. Based on the above analysis, when the content of graphite film in the composites increased, the mechanical properties of the composites decreased, and the composites are not easy to be broken but easy to be layered. 

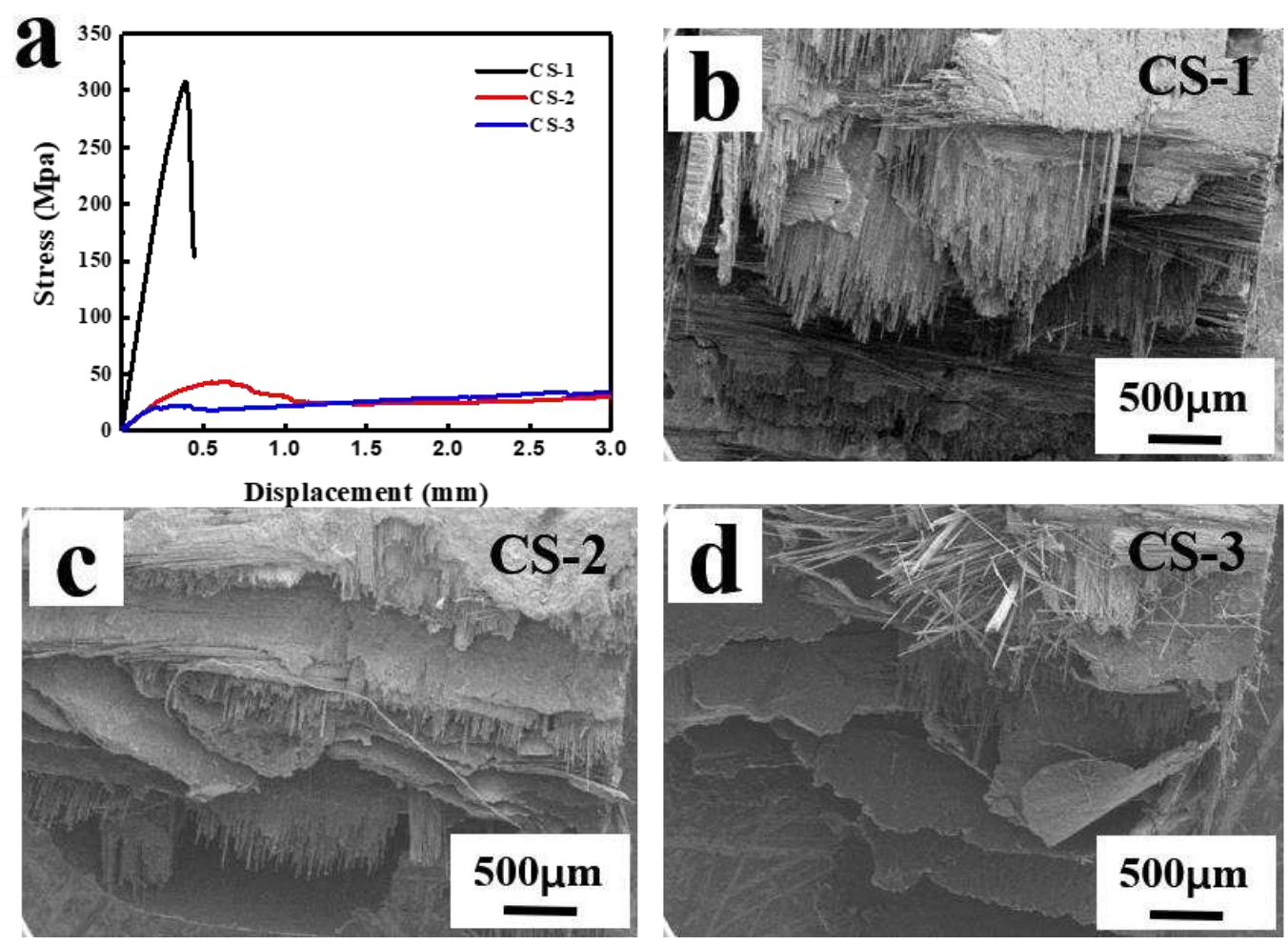

Fig. 5 (a) Flexural stress-displacement curves and SEM images on the fracture surfaces of three

materials: (b) CS-1, (c) CS-2 and (d) CS-3.

\subsection{Thermal conductivity and anti-ablation performance of $\mathrm{C} / \mathrm{SiC}$ composites}

Table 4 indicated the thermal diffusivity and thermal conductivity of $\mathrm{C} / \mathrm{SiC}$ composites at room temperature. It can be found that the thermal diffusivity and thermal conductivity of $\mathrm{C} / \mathrm{SiC}$ composites increase along the axial direction of the fibers. The thermal conductivity of CS-3 is significantly improved to $333.34 \pm 10.24 \mathrm{~W} /(\mathrm{m} \cdot \mathrm{K})$ from $9.78 \pm 0.05 \mathrm{~W} /(\mathrm{m} \cdot \mathrm{K})$, which indicates that the graphite films play an important role in improving the axial thermal conductivity of the C/SiC composites. Fig. 6 presents the schematic diagram for thermally conductive mechanism of the $\mathrm{C} / \mathrm{SiC}$ composites, and the fundamental reason for heat conduction is the vibration of the lattice point[21]. According to frequency, lattice vibration could be divided into audio branch and optical frequency branch, and at ultra-high temperature, the energy of the optical lattice wave is relatively weak, at this time the acoustic lattice wave plays a decisive role in the heat transfer. The 
interaction between phonons plays a major role in heat conduction, and the transmission efficiency depends on the mean free path of phonons[23]. In the graphite film, the better the regularity and development of graphite crystallite arrangement, the larger the average crystallite size and mean free path of phonons, and the better the thermal conductivity of the corresponding materials.

Since graphite films having good crystal orientation and high thermal conductivity, the axial thermal conductivity at room temperature could reach $1100 \mathrm{~W} /(\mathrm{m} \cdot \mathrm{K})$, thus increasing the graphite films help to improve the axial thermal conductivity of the $\mathrm{C} / \mathrm{SiC}$ composites. In addition, the graphite films have significant anisotropy, and the radial thermal expansion coefficient is significantly higher than that on the axial direction. Thus, the orientation of carbon fiber has important influence on the thermal conductivity of $\mathrm{C} / \mathrm{SiC}$ composite in different directions. Meantime, carbon fibers also have good anisotropy, so the axial thermal conductivity of the carbon fiber plays a major role in the direction perpendicular to the needle, while the parallel direction is the major role in the radial heat conduction between the carbon fibers. Therefore, the anisotropy of graphite film and carbon fibers makes the thermal conductivity of $\mathrm{C} / \mathrm{SiC}$ composites vary greatly in two different directions, that is, the thermal conductivity of the final obtained composites perpendicular to the direction of the needle is much higher than that of parallel to the needle. To above, the thermal conductivity along the fiber axial direction of the highly thermally conductive $\mathrm{C} / \mathrm{SiC}$ composites prepared with graphite film and carbon fibers is higher than that along the radial direction of the fibers, and with increasing the content of graphite film, the axial direction thermal conductivity is enhanced. And the high thermal conductivity of composites may help improve the surface ablation resistance. 
Table 4 Axial (//) and radial $(\perp)$ Thermal diffusivity and Thermal conductivity of samples

\begin{tabular}{ccccc}
\hline \multirow{2}{*}{ Samples } & \multicolumn{2}{c}{ Thermal diffusivity $\left(\mathrm{mm}^{2} / \mathrm{s}\right)$} & \multicolumn{2}{c}{ Thermal conductivity $(\mathrm{W} /(\mathrm{mK}))$} \\
\cline { 2 - 5 } & \multicolumn{1}{c}{$1 / 40 \pm 0.05$} & $1.634 \pm 0.002$ & $9.78 \pm 0.05$ & 1 \\
\hline CS-1 & $35.60 \pm 0.81$ & $1.315 \pm 0.001$ & $51.55 \pm 0.91$ & $1.90 \pm 0.01$ \\
CS-2 & & & & \\
CS-3 & $230.21 \pm 10.24$ & $1.792 \pm 0.002$ & $333.34 \pm 10.24$ & $2.50 \pm 0.03$ \\
\hline
\end{tabular}
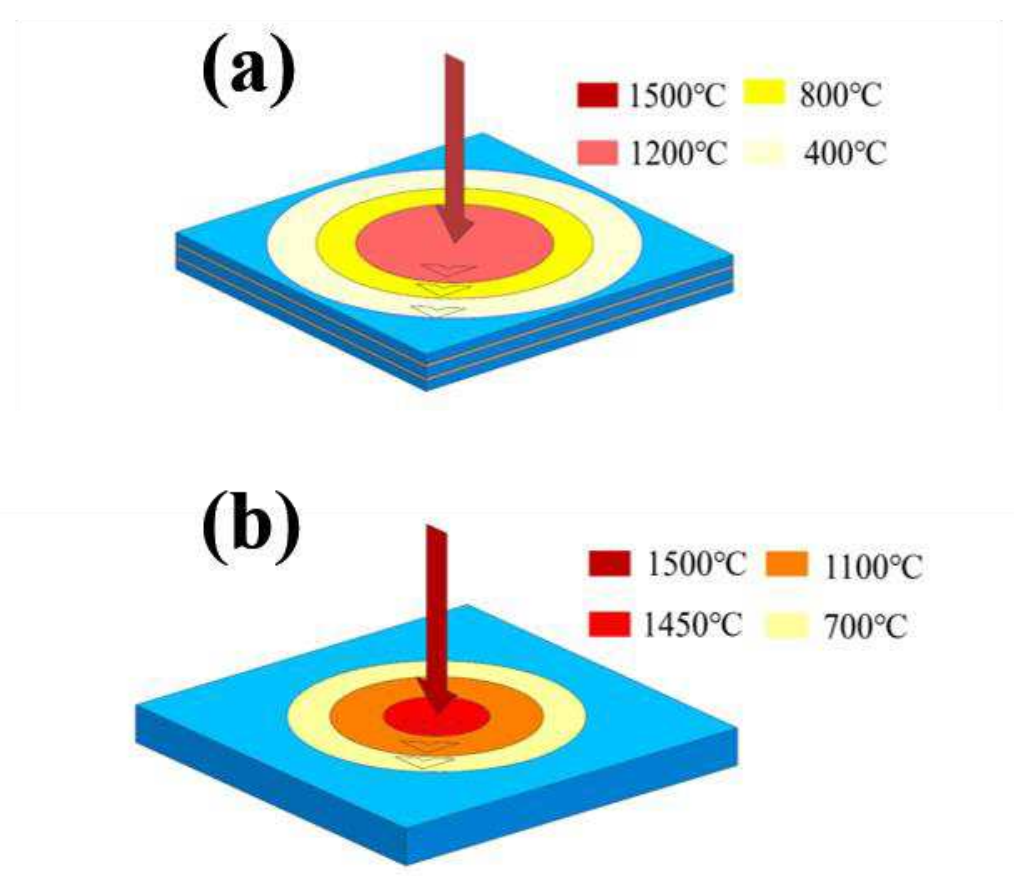

Fig. 6 The thermally conductive mechanism of materials: (a) high thermal $\mathrm{C} / \mathrm{SiC}$ composite (b) $\mathrm{C} / \mathrm{SiC}$ composite.

The ablation resistance of the $\mathrm{C} / \mathrm{SiC}$ composites was measured for $600 \mathrm{~s}$ at $1500{ }^{\circ} \mathrm{C}$ with a plasma generator as the ablation equipment. The mass and linear ablation rates of CS-1, CS-2 and CS-3 are shown in Fig. 7. It is clear that the mass and linear ablation rates of the $\mathrm{C} / \mathrm{SiC}$ composites exhibit a decreasing trend with the increase of the graphite films content. To further analyze the reasons, the microstructures of the ablation centers of the three materials were characterized by 
SEM (Fig. 8). The surface is covered with a glass layer after ablation, and a little penetrative cracks or fiber breakage could be observed on the surface (Fig. 8a). And the EDS result indicates that the substance is similar to $\mathrm{Si}-\mathrm{O}$ glass forms exiting on the surface of the materials after ablation, which may be owing to the oxidation of $\mathrm{SiC}[24]$. Besides, some of molten $\mathrm{SiO}_{2}$ layer could be blow away by the gas flow and formed the ablated pits, which could lead to the poor ablation resistance of CS-1. As shown in Fig. 8b, as the graphite film content increased, the size of ablated pits on surface of CS-2 became smaller and the number is less. Those are consistent with the results of the ablation rate, which further demonstrated that the ablation resistance of the materials is improved due to the increase of graphite film. Combined with Table 4, it could be found that with the graphite film increasing, the thermal conductivity of the materials increased, which could quickly dissipate the heat of ablation flame burning in the center of the materials, thereby reduced the damage of the surface of the composites and improved the ablation resistance.

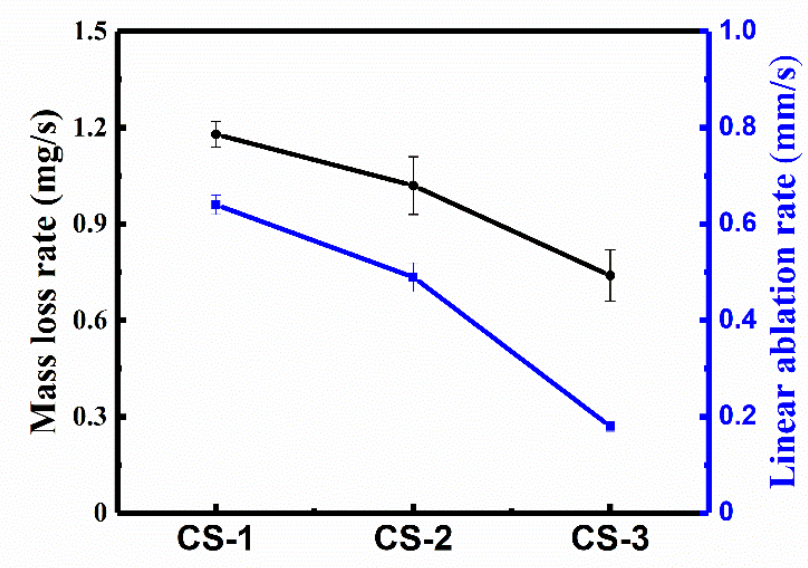

Fig. 7 Mass loss rates and linear ablation rates of three materials. 

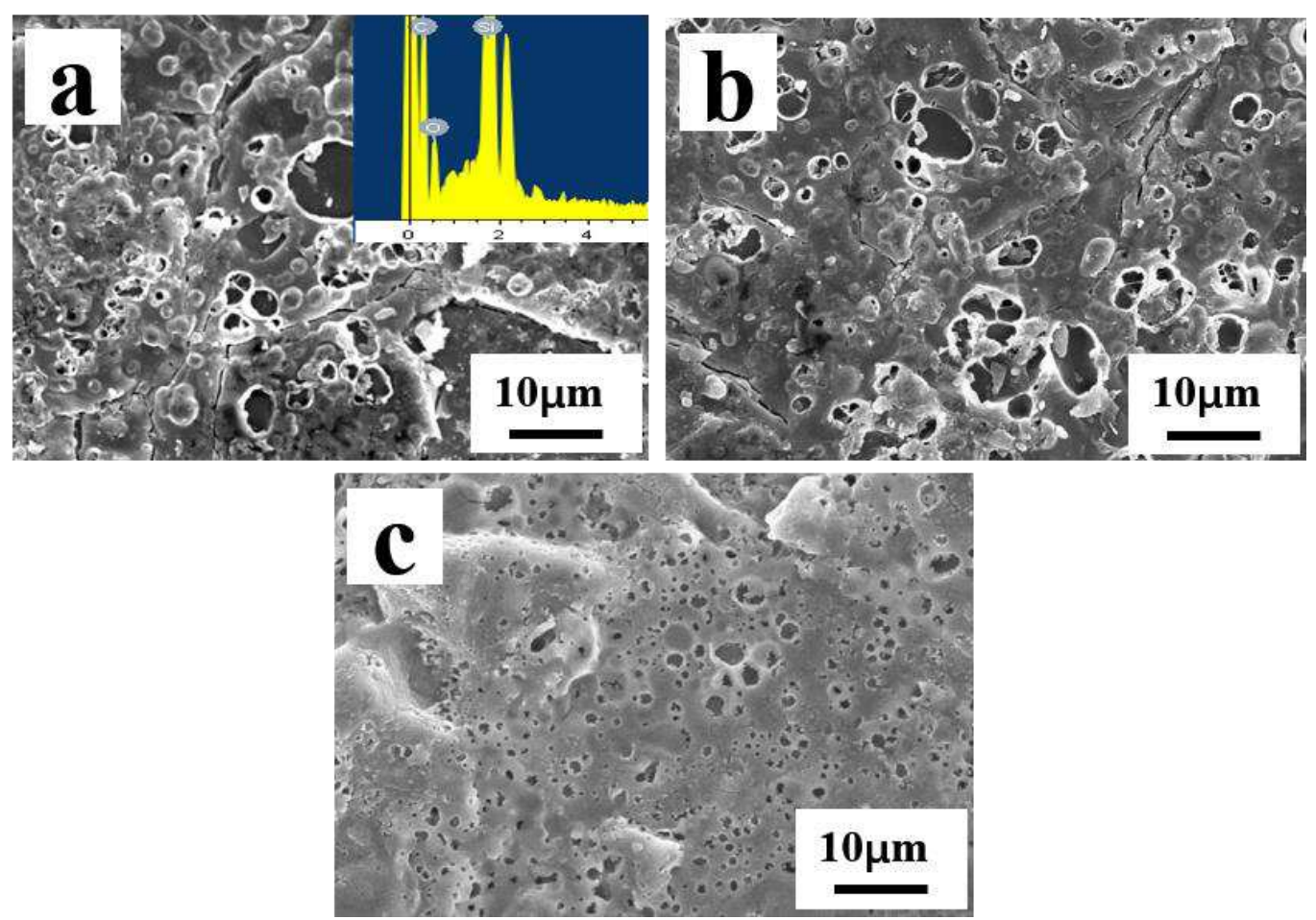

Fig. 8 SEM images of the cross section of three materials after ablation at $1500{ }^{\circ} \mathrm{C}$ : (a) CS-1, (b) CS-2

and (c) CS-3.

\section{Conclusion}

$\mathrm{C} / \mathrm{SiC}$ composites with different quantity ratios of 2D fiber cloth to HTC graphite film were fabricated and the microstructures, mechanical properties and the ablation behavior of composites at $1500{ }^{\circ} \mathrm{C}$ for $600 \mathrm{~s}$ via plasma art-jet flame ablation test were investigated. On the one hand, with the increase of the graphite films content, the bonding degree of carbon fiber cloth and the graphite film in the $\mathrm{C} / \mathrm{SiC}$ composites decreased, and the bending strength also drops to $20.6 \mathrm{MPa}$. On the other hand, the addition of graphite films significantly improved the thermal conductivity of the $\mathrm{C} / \mathrm{SiC}$ composites, and greatly enhanced their ablation resistance, which may promote their potential for application in ultra-high temperature environments.

\section{Reference}

[1] S. Tang, J. Deng, S. Wang, W. Liu, Journal of the American Ceramic Society, 90 (2007) 3320-3322. 
[2] C. Zhou, Z. Changrui, H. Haifeng, Z. Yudi, W. Zhiyi, Materials Science and Engineering: A, 488 (2008) 569-572.

[3] H.-T. Wu, X. Wei, S.-Q. Yu, W.-G. Zhang, Journal of Inorganic Materials, 26 (2011) 852-856.

[4] T. Li, X. Yu, H. Liu, H. Yang, Y. Li, Composite Structures, 189 (2018) 378-385.

[5] G. Zhang, Z. Deng, N. Kondo, J. Yang, T. Ohji, Journal of the American Ceramic Society, 83 (2000) 2330-2332.

[6] J. Wu, Z. Kou, G. Cui, Industrial Lubrication and Tribology, 68 (2016) 212-219.

[7] T. Li, J. Mo, X. Yu, T. Suo, Y. Li, Composites Part A: Applied Science and Manufacturing, 88 (2016) $19-26$.

[8] M.-y. Zhang, K.-z. Li, X.-h. Shi, W.-l. Tan, Materials \& Design, 122 (2017) 322-329.

[9] T. Naganuma, K. Naito, J.-M. Yang, J. Kyono, D. Sasakura, Y. Kagawa, Composites Science and Technology, 69 (2009) 1319-1322.

[10] F. Monteverde, Corrosion Science, 47 (2005) 2020-2033.

[11] J. Sun, W. Liu, Acta Physica Sinic, 63 (2014) 094401-094408.

[12] N. Mehra, L. Mu, T. Ji, X. Yang, J. Kong, J. Gu, J. Zhu, Applied Materials Today, 12 (2018) 92-130.

[13] X. Zhang, Q. Qu, J. Han, W. Han, C. Hong, Scripta Materialia, 59 (2008) 753-756.

[14] J. Marschall, A. Chamberlain, D. Crunkleton, B. Rogers, Journal of Spacecraft and Rockets, 41 (2004) 576-581.

[15] J. Sun, Q. Zhu, AIP Advances, 9 (2019) 1-12.

[16] D. Baruzzo, D. Minichelli, S. Bruckner, L. Fedrizzi, A. Bachiorrini, S. Maschio, Journal of hazardous materials, 134 (2006) 202-210.

[17] P. Ndiba, L. Axe, T. Boonfueng, Environment Science Technology, 42 (2008) 920-926. 
[18] W. Krenkel, F. Berndt, Materials Science and Engineering: A, 412 (2005) 177-181.

[19] X. Yang, C. Liang, T. Ma, Y. Guo, J. Kong, J. Gu, M. Chen, J. Zhu, Advanced Composites and Hybrid Materials, 1 (2018) 207-230.

[20] Y. Qian, W. Zhang, M. Ge, X. Wei, Journal of Advanced Ceramics, 2 (2013) 157-161.

[21] Y. ACARI, A. UEDA, S. NACAl, Journal of Applied Polymer Science, 49 (1993) 1625-1634.

[22] X. Han, Y. Huang, Q. Gao, M. Yu, X. Chen, Industrial \& Engineering Chemistry Research, 57 (2018) 10365-10371.

[23] W. Hong, K. Gui, P. Hu, X. Zhang, S. Dong, Journal of Advanced Ceramics, 6 (2017) 110-119.

[24] C. Hu, S. Pang, S. Tang, S. Wang, H. Huang, H.-M. Cheng, Corrosion Science, 80 (2014) 154-163. 
Figures

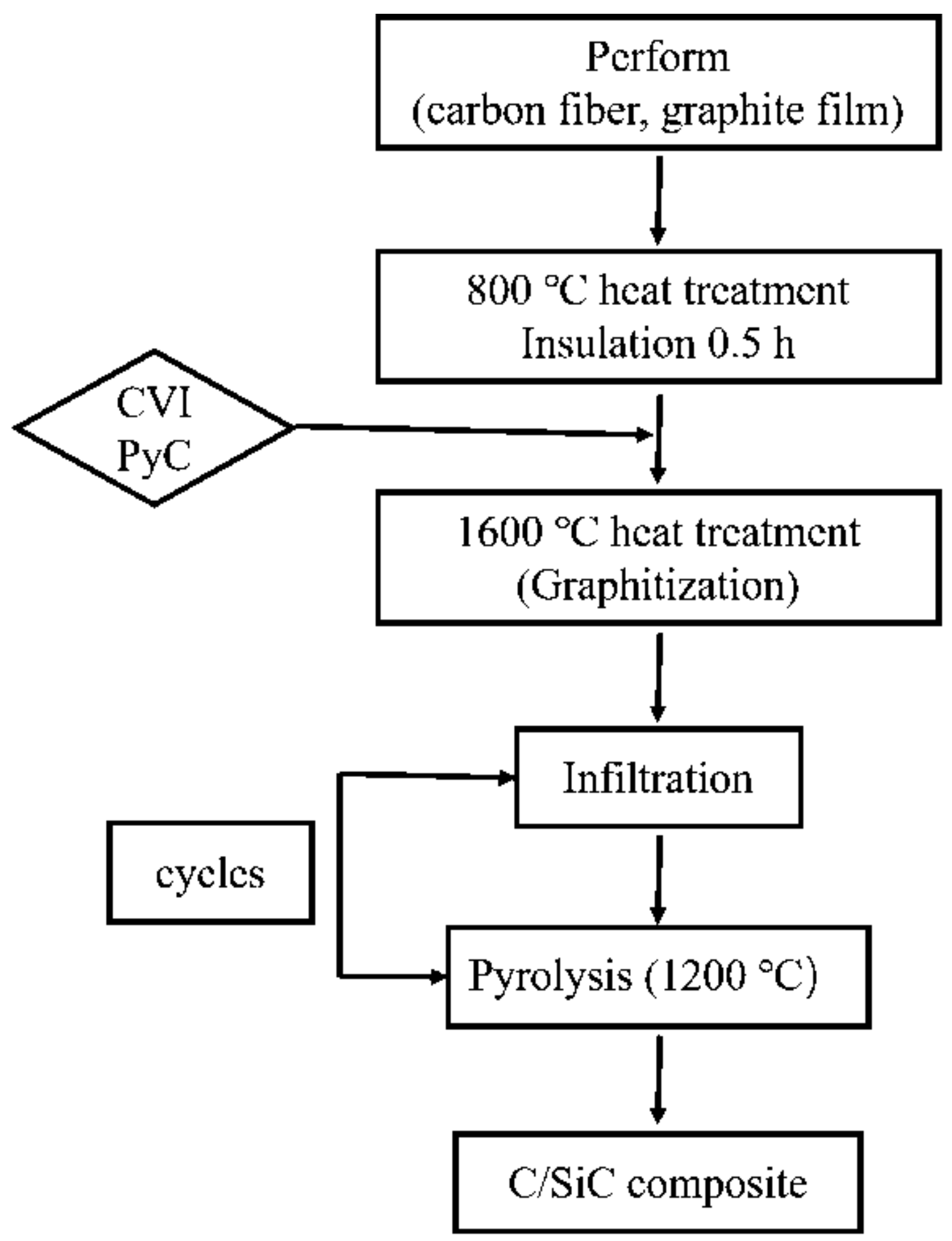

Figure 1

Process flow chart of HTC C/SiC composites 


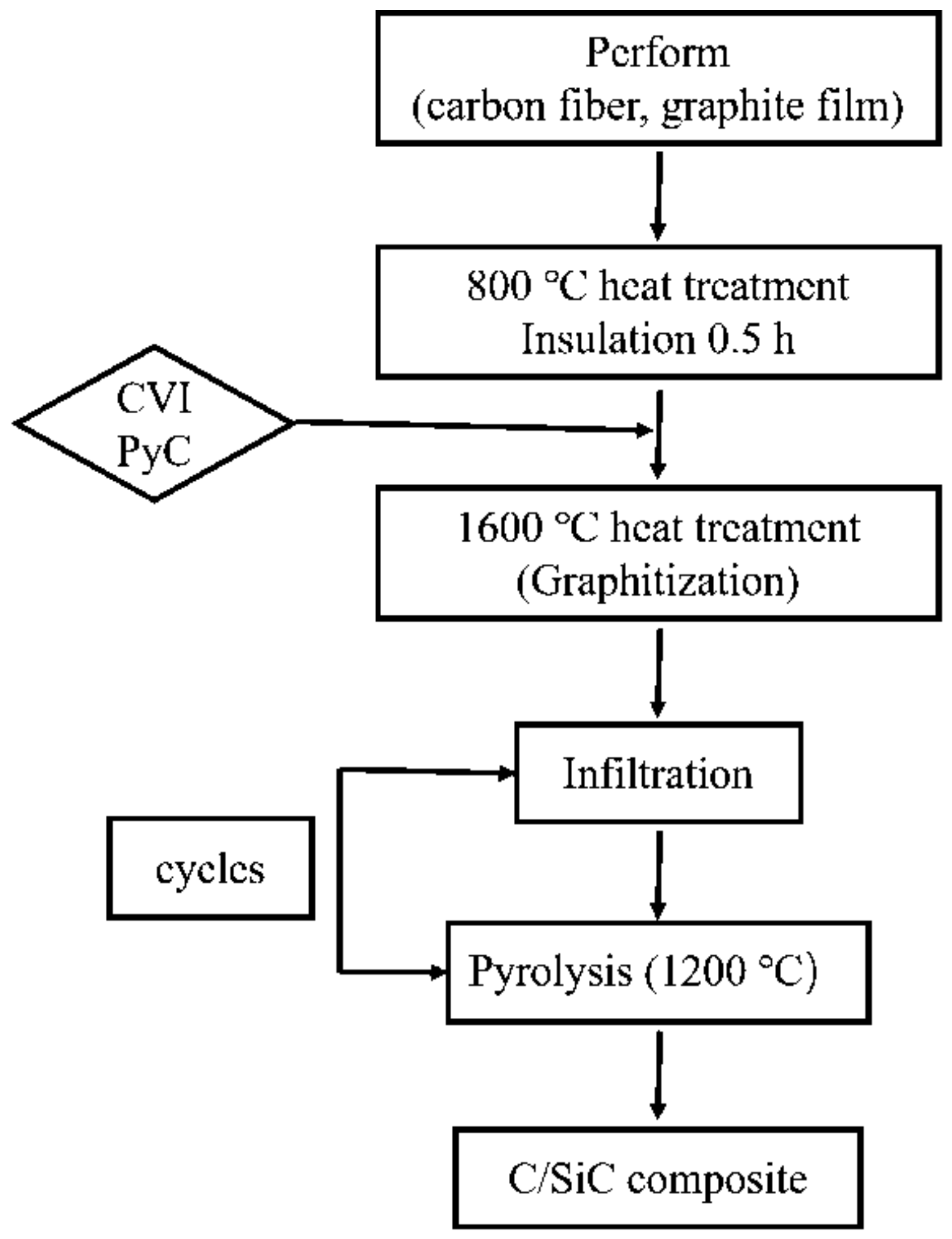

Figure 1

Process flow chart of HTC C/SiC composites 


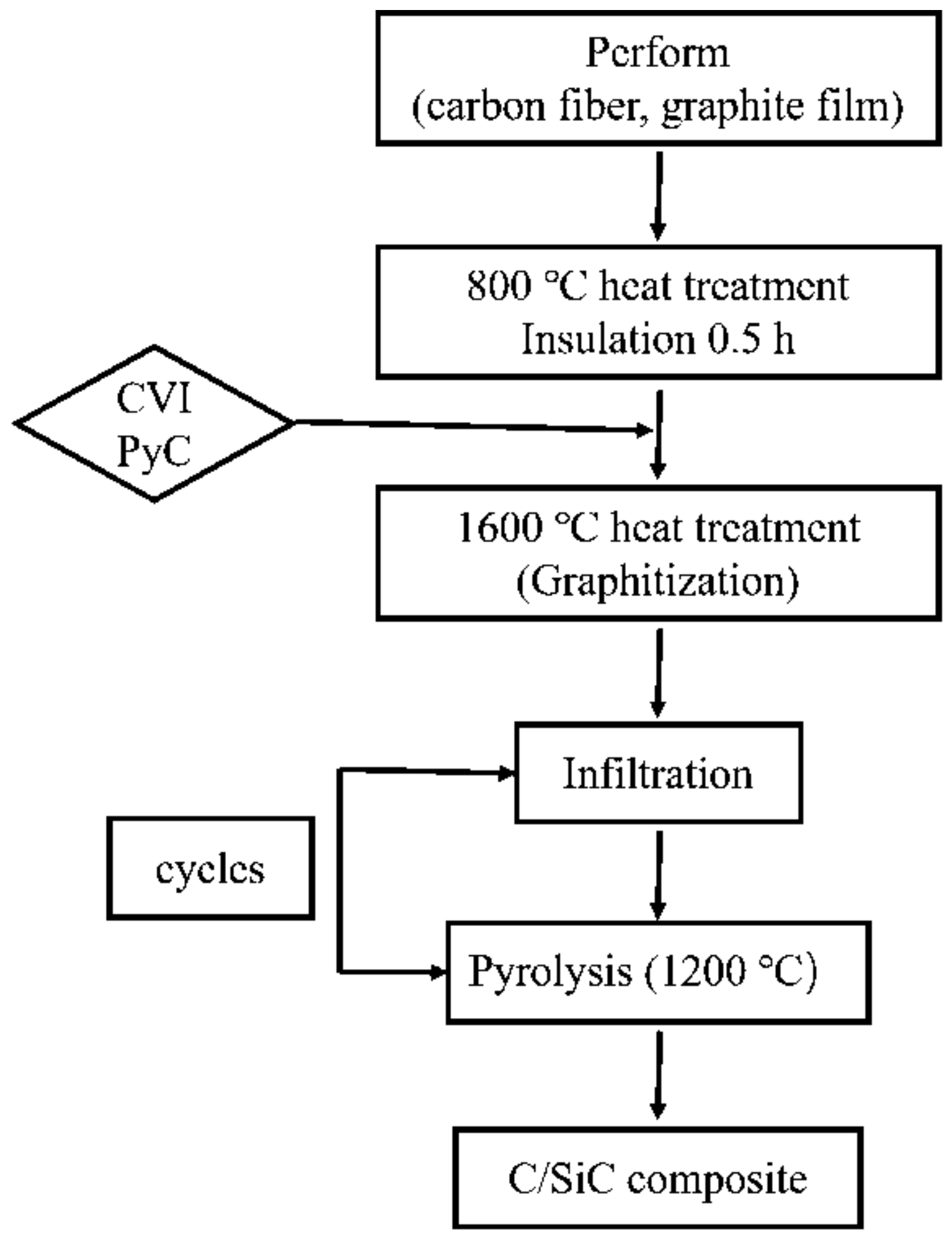

Figure 1

Process flow chart of HTC C/SiC composites 


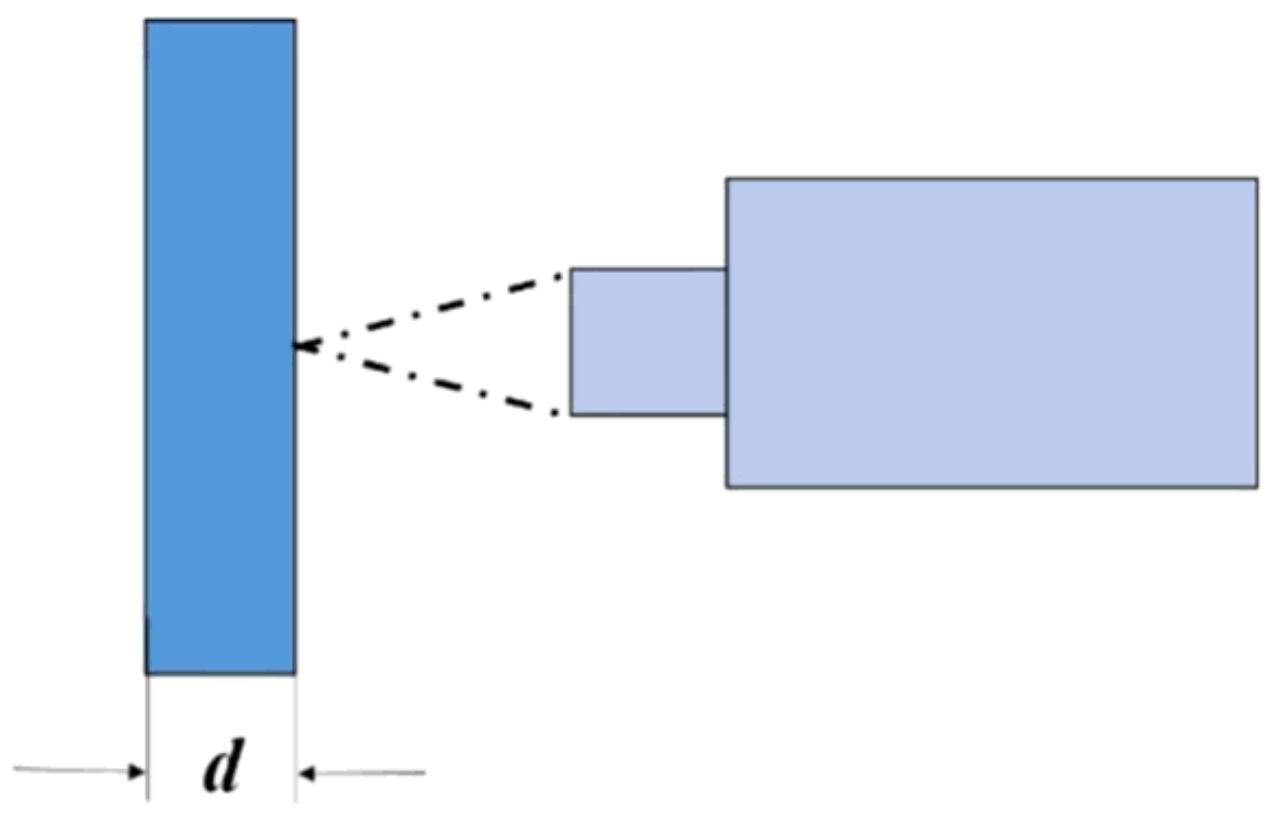

Figure 2

The mechanism of the laser flash method[19]

Uniform pulse heating Specimen

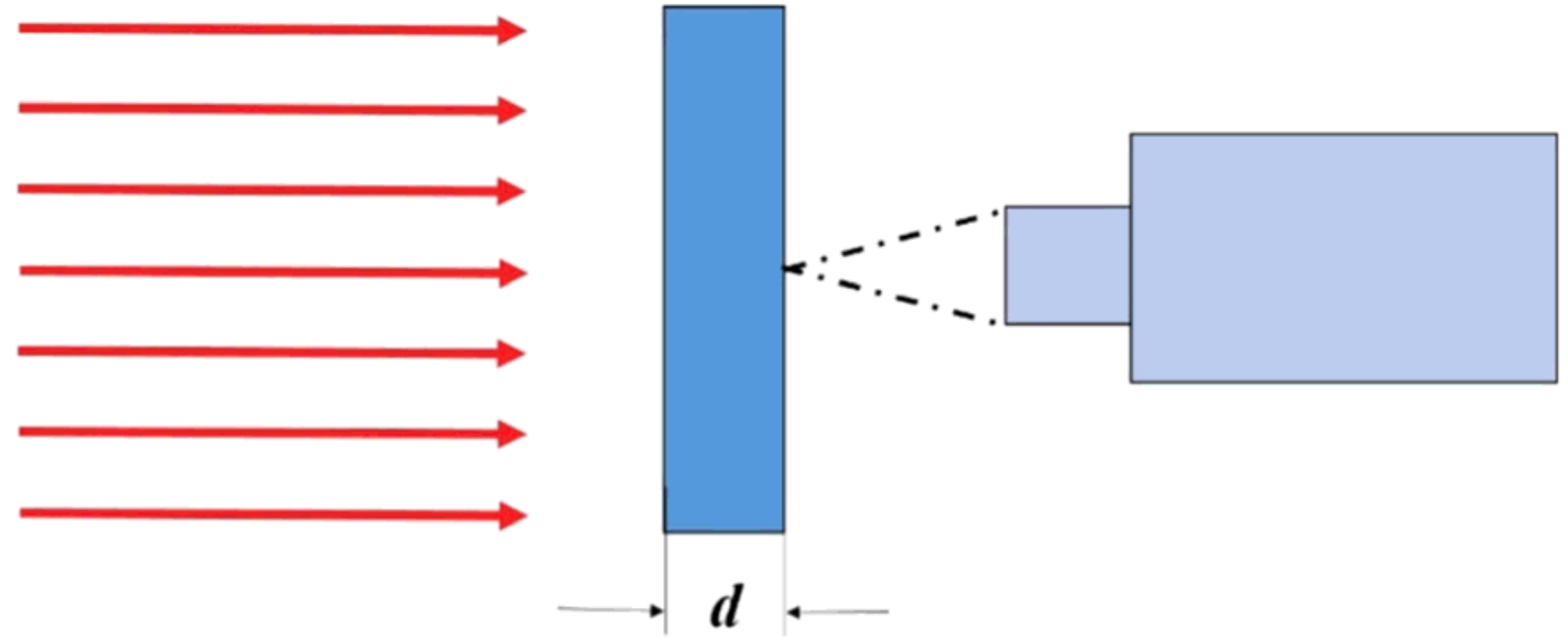

Figure 2

The mechanism of the laser flash method[19] 


\section{Uniform pulse heating}
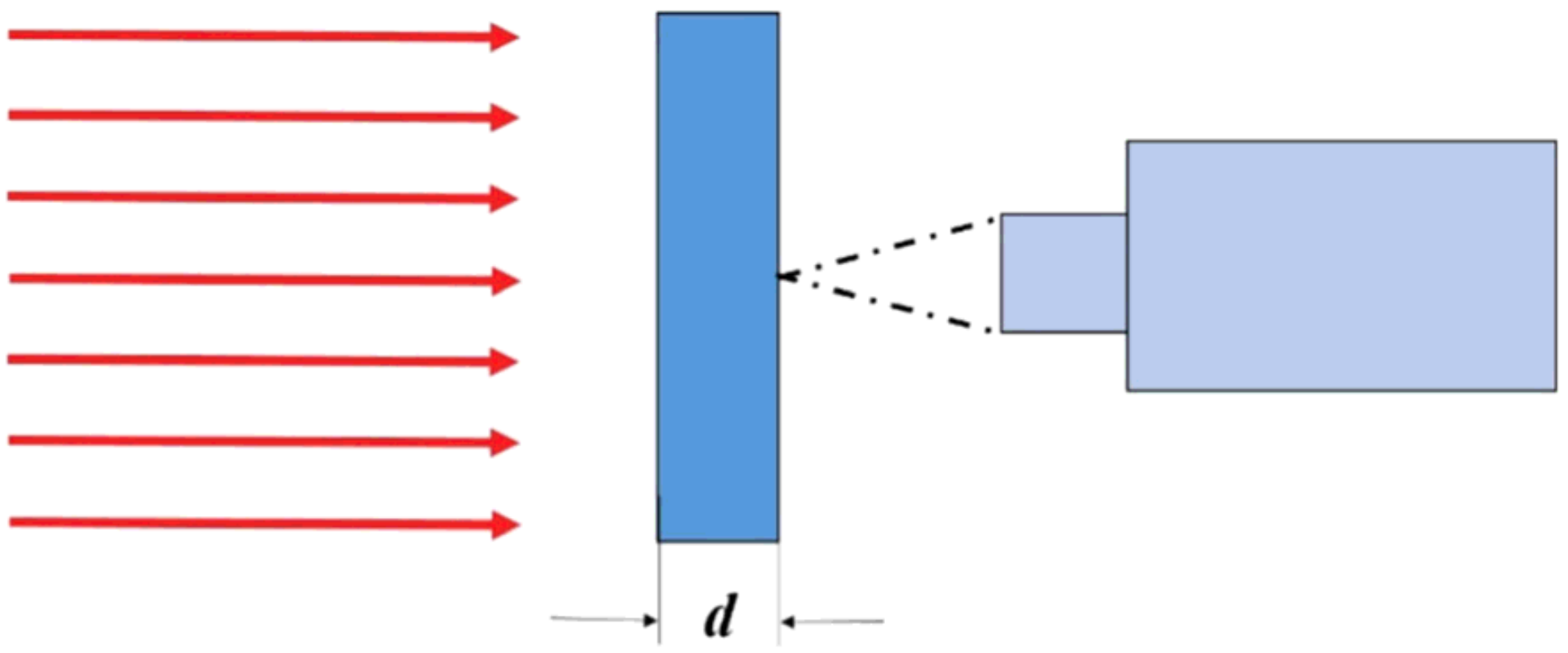

Figure 2

The mechanism of the laser flash method[19]
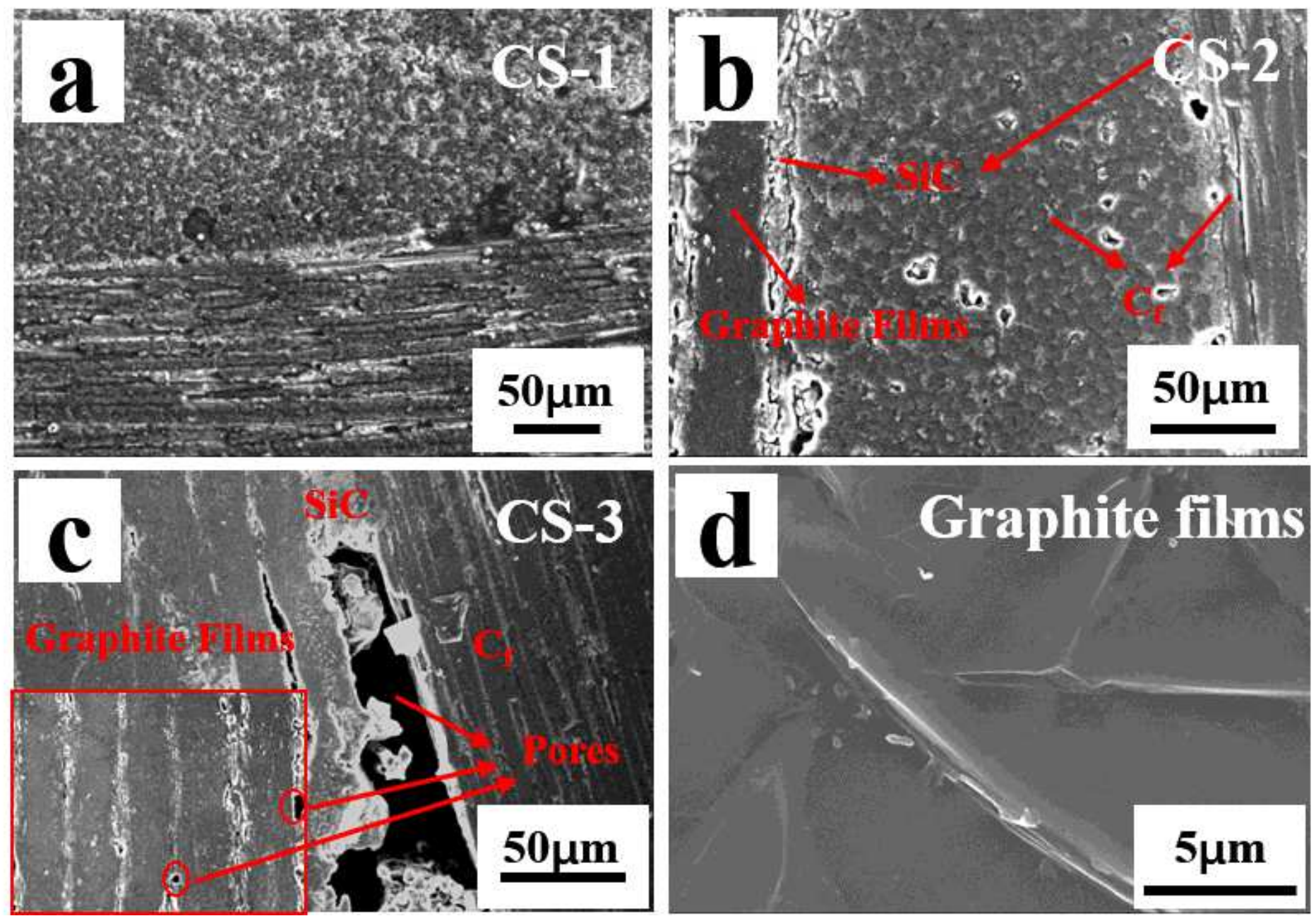


\section{Figure 3}

SEM images of polished cross-section microstructure for (a) CS-1, (b) CS-2, (c) CS-3, and (d) Graphite films.
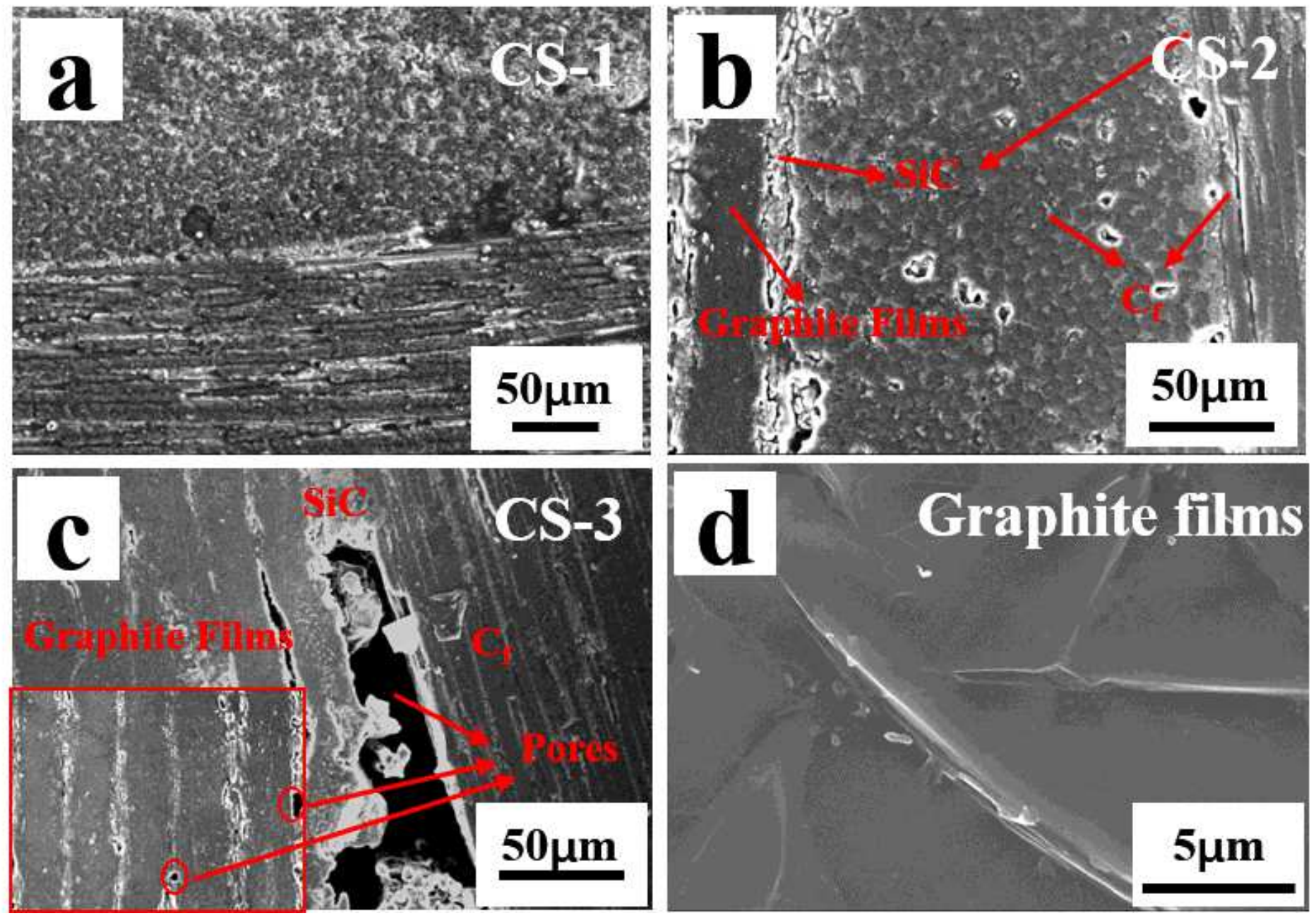

Figure 3

SEM images of polished cross-section microstructure for (a) CS-1, (b) CS-2, (c) CS-3, and (d) Graphite films. 

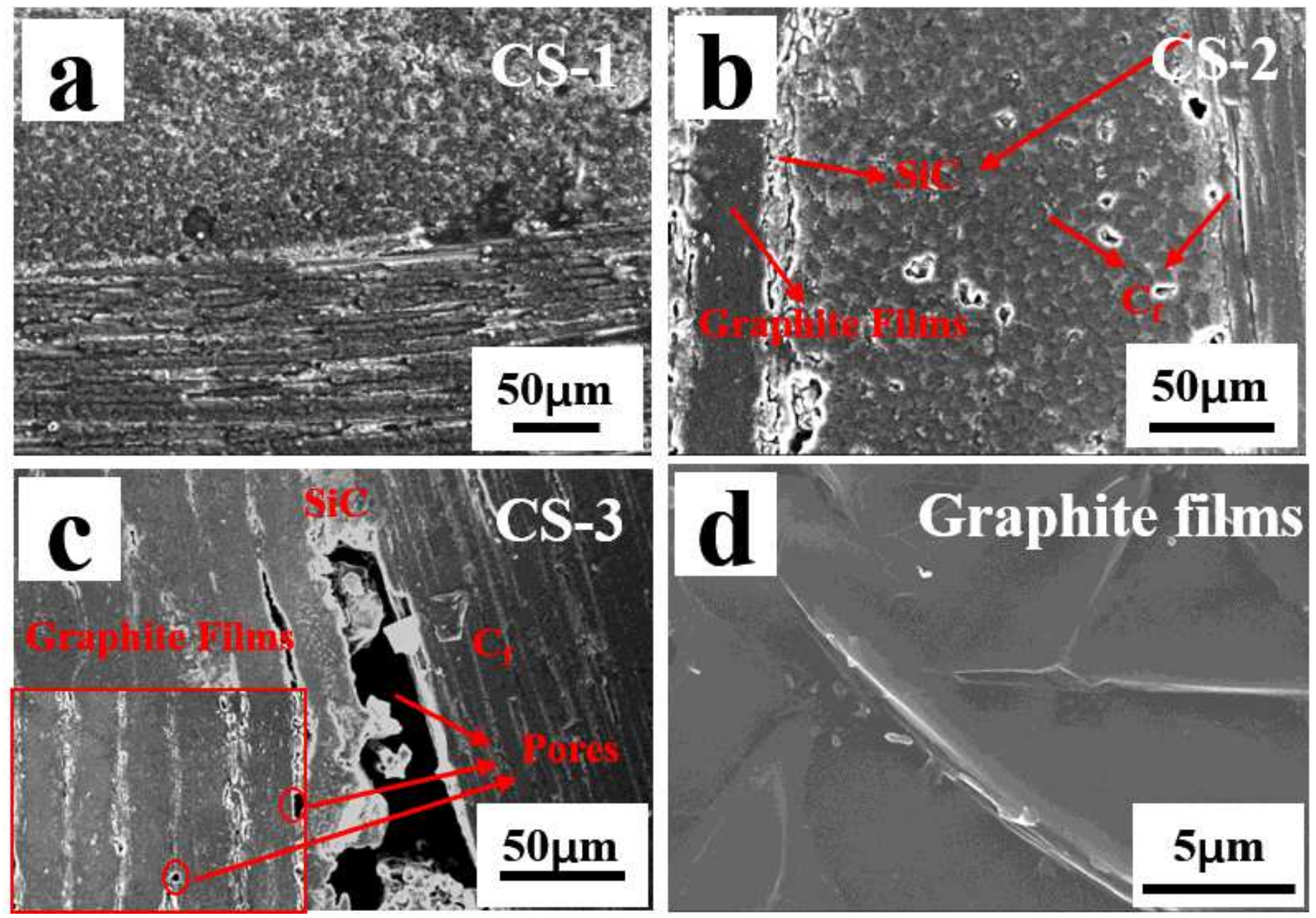

Figure 3

SEM images of polished cross-section microstructure for (a) CS-1, (b) CS-2, (c) CS-3, and (d) Graphite films. 


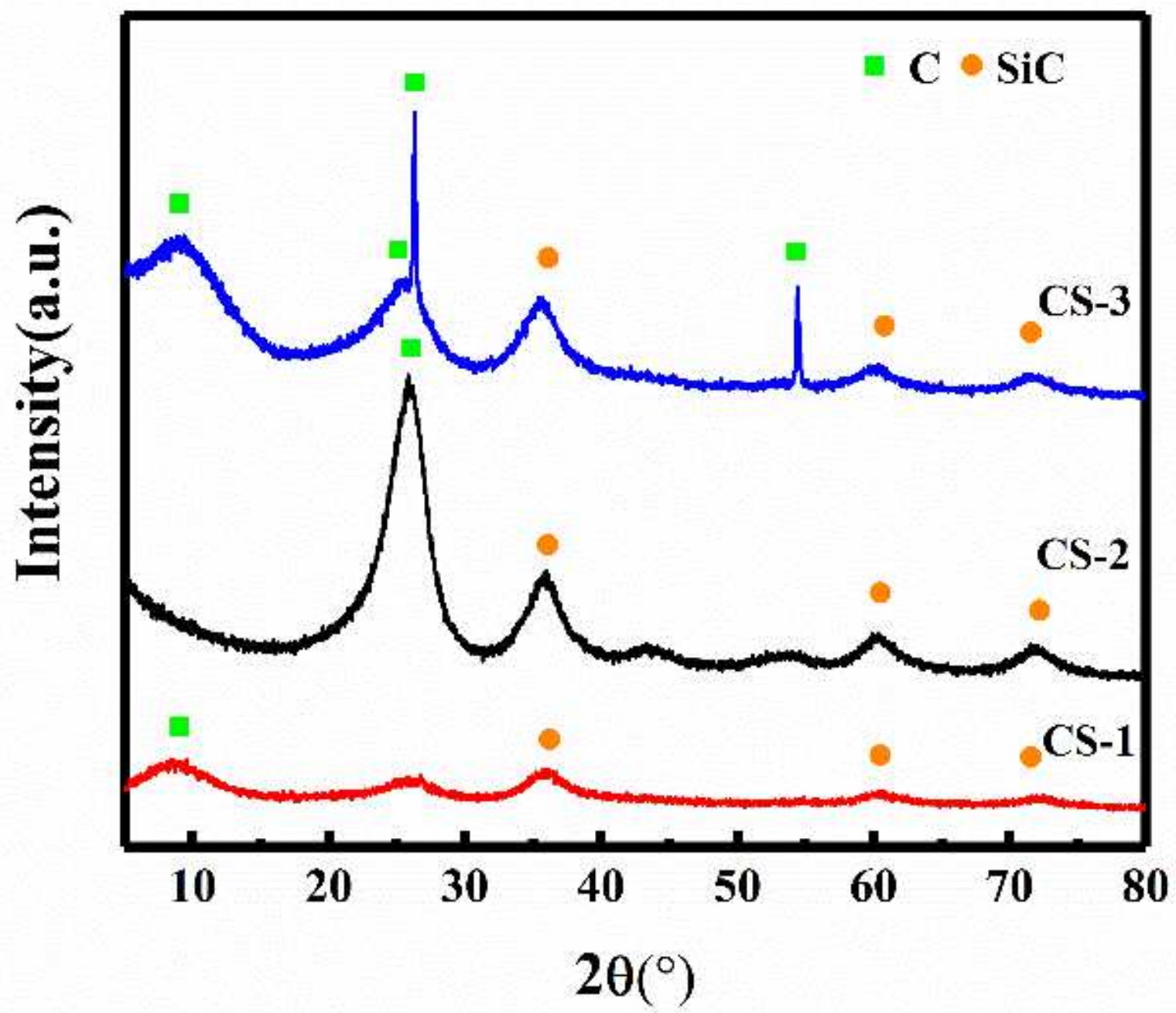

Figure 4

$\mathrm{XRD}$ analysis of three materials. 


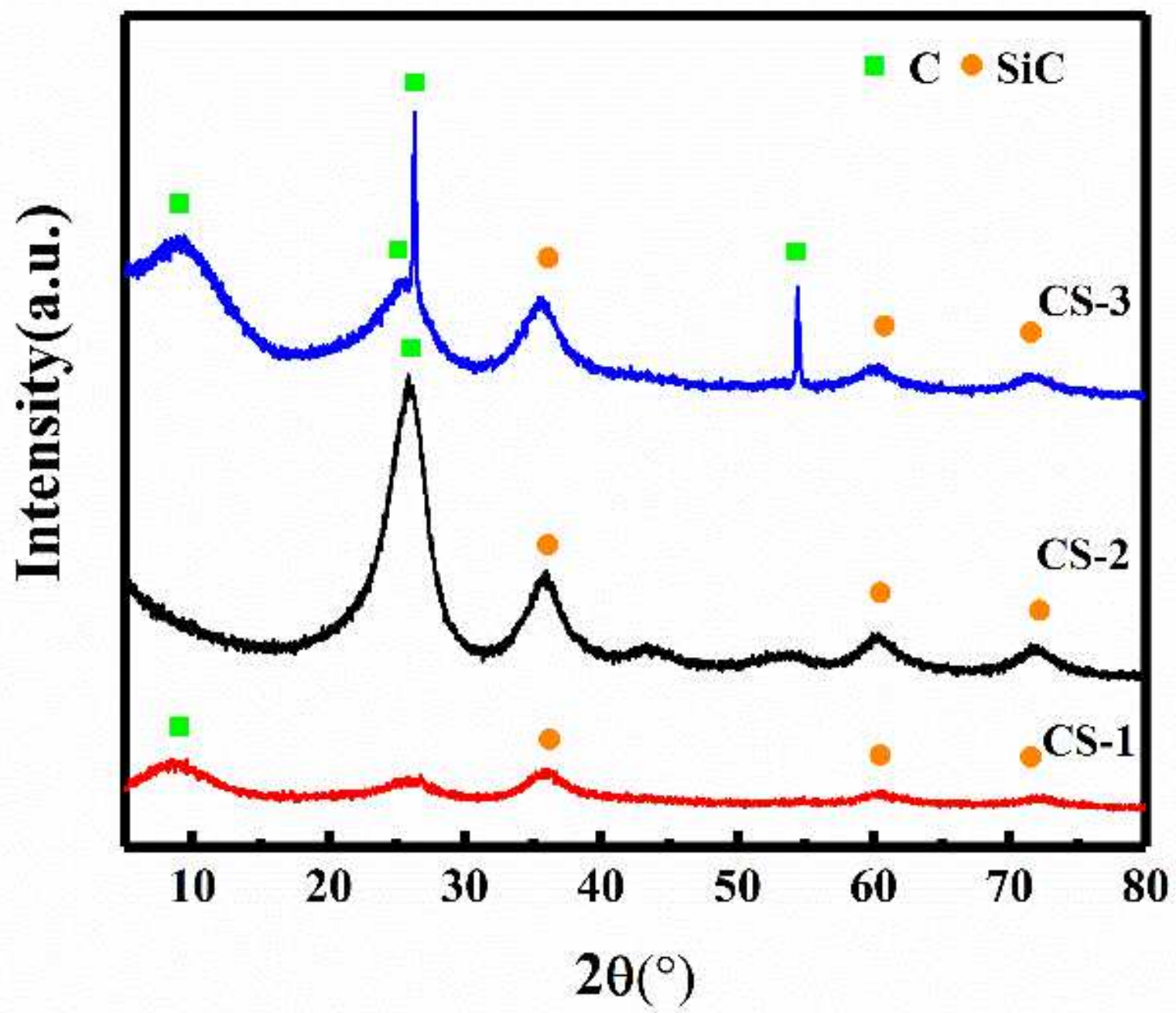

Figure 4

$\mathrm{XRD}$ analysis of three materials. 


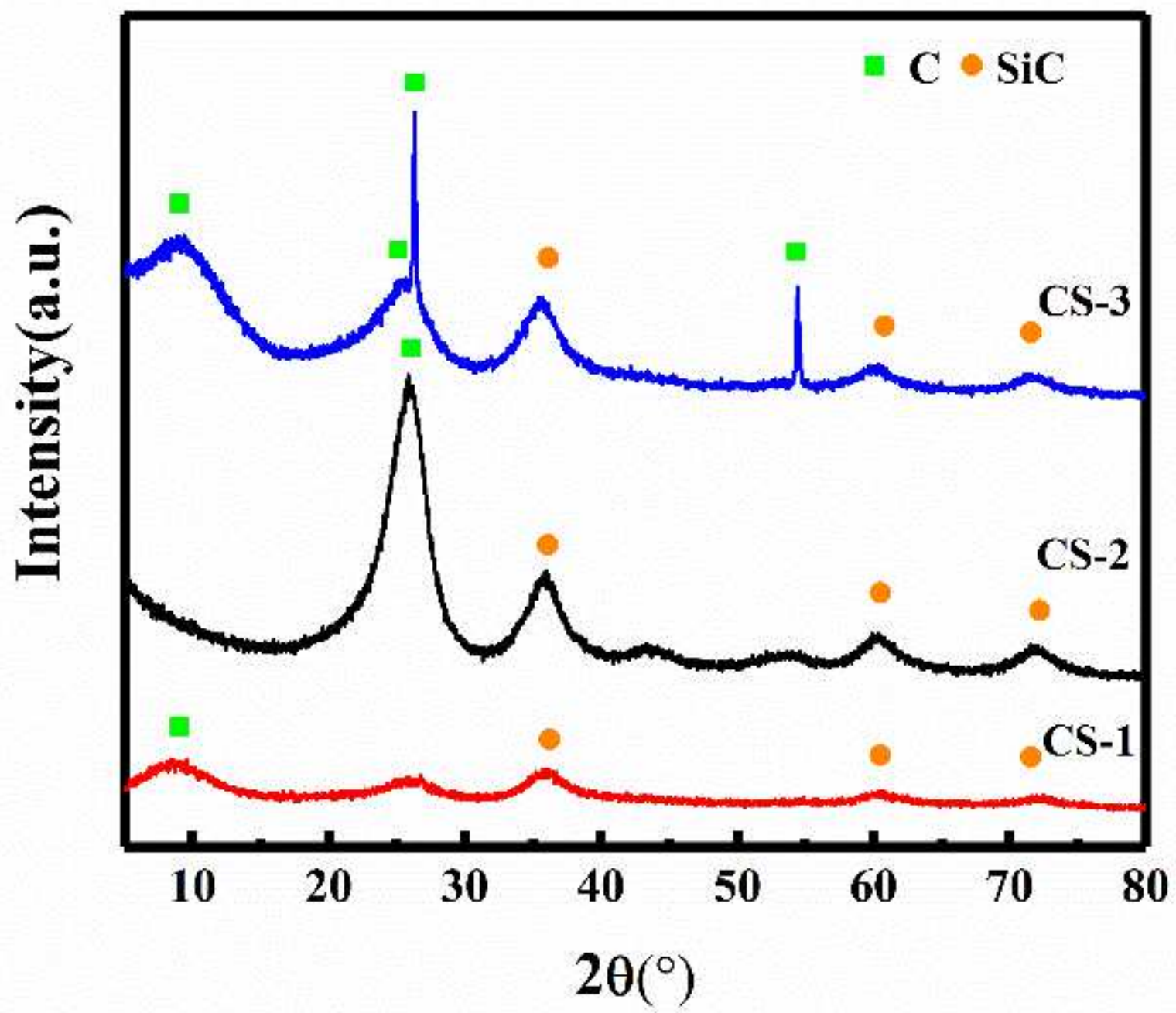

Figure 4

$\mathrm{XRD}$ analysis of three materials. 

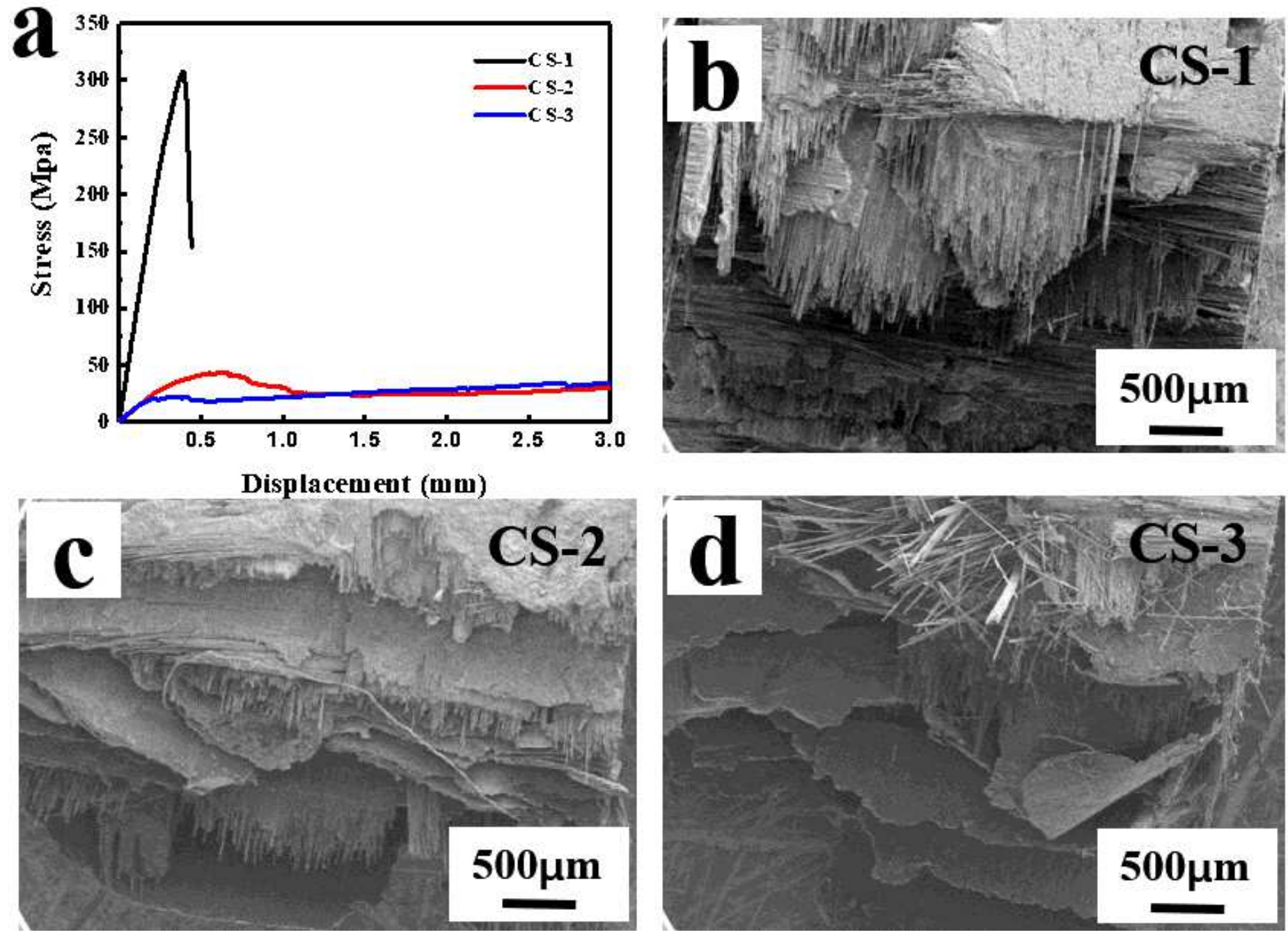

Figure 5

(a) Flexural stress-displacement curves and SEM images on the fracture surfaces of three materials: (b) CS-1, (c) CS-2 and (d) CS-3. 

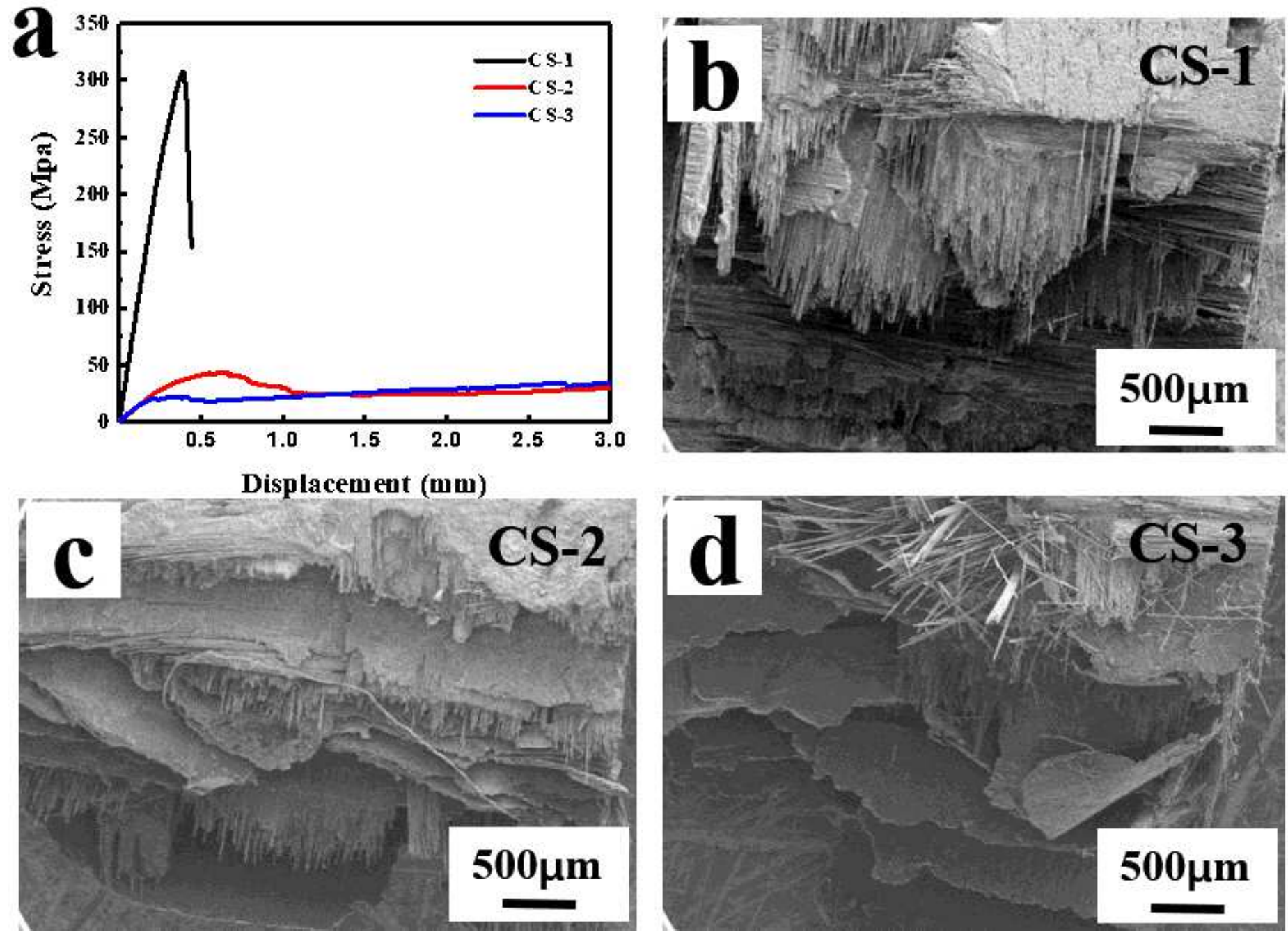

Figure 5

(a) Flexural stress-displacement curves and SEM images on the fracture surfaces of three materials: (b) CS-1, (c) CS-2 and (d) CS-3. 

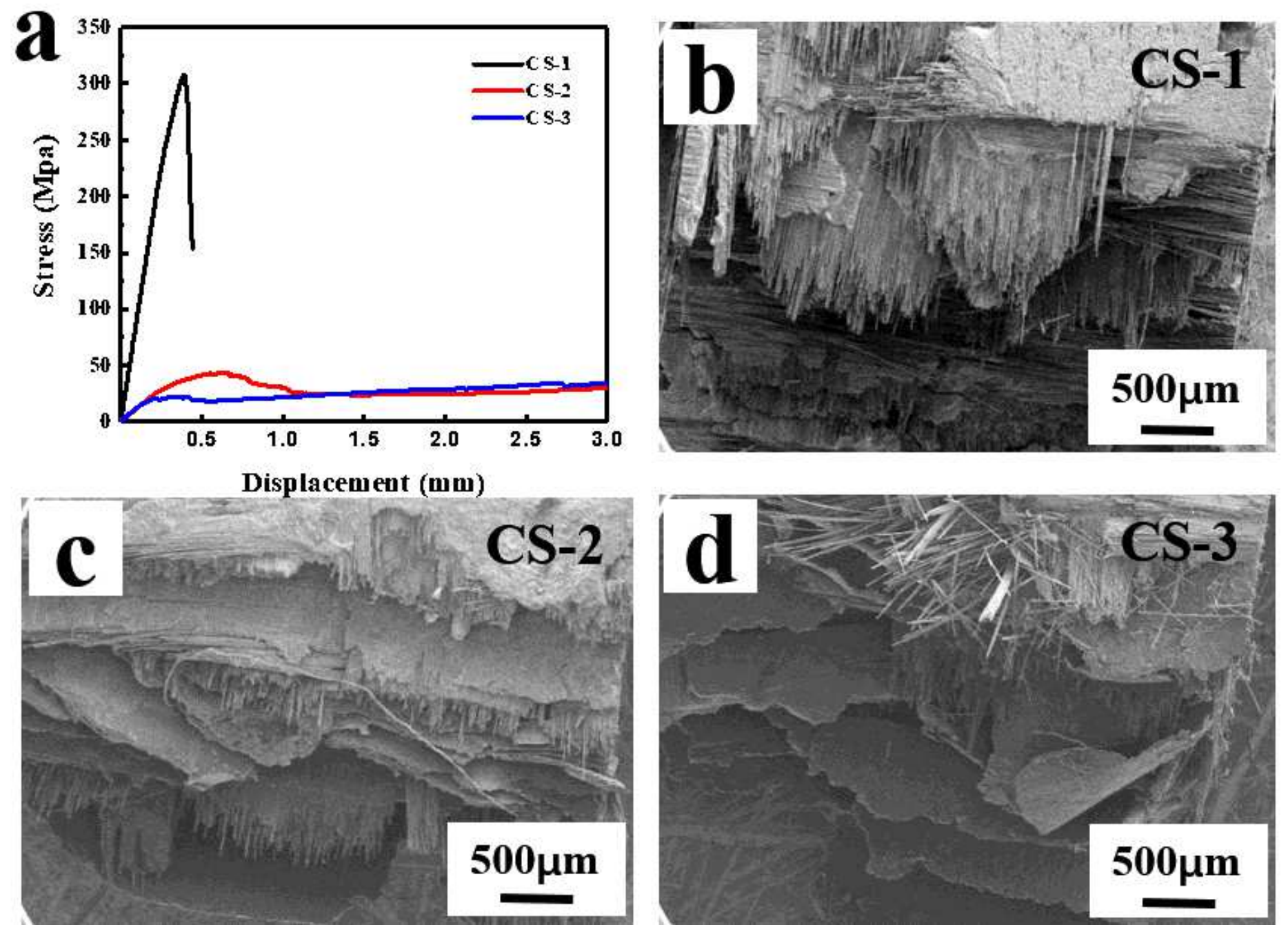

Figure 5

(a) Flexural stress-displacement curves and SEM images on the fracture surfaces of three materials: (b) CS-1, (c) CS-2 and (d) CS-3. 

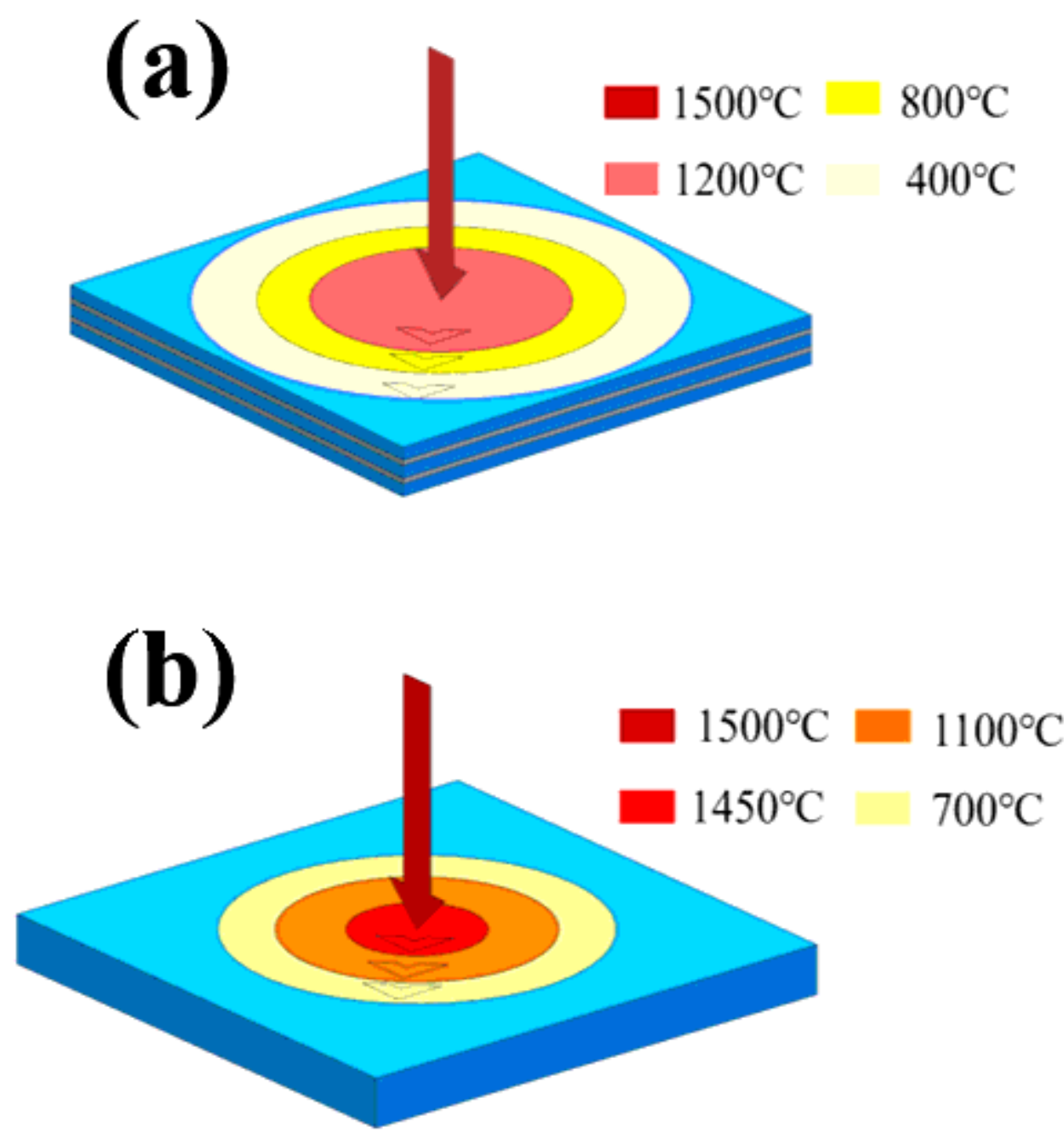

Figure 6

The thermally conductive mechanism of materials: (a) high thermal C/SiC composite (b) C/SiC composite. 

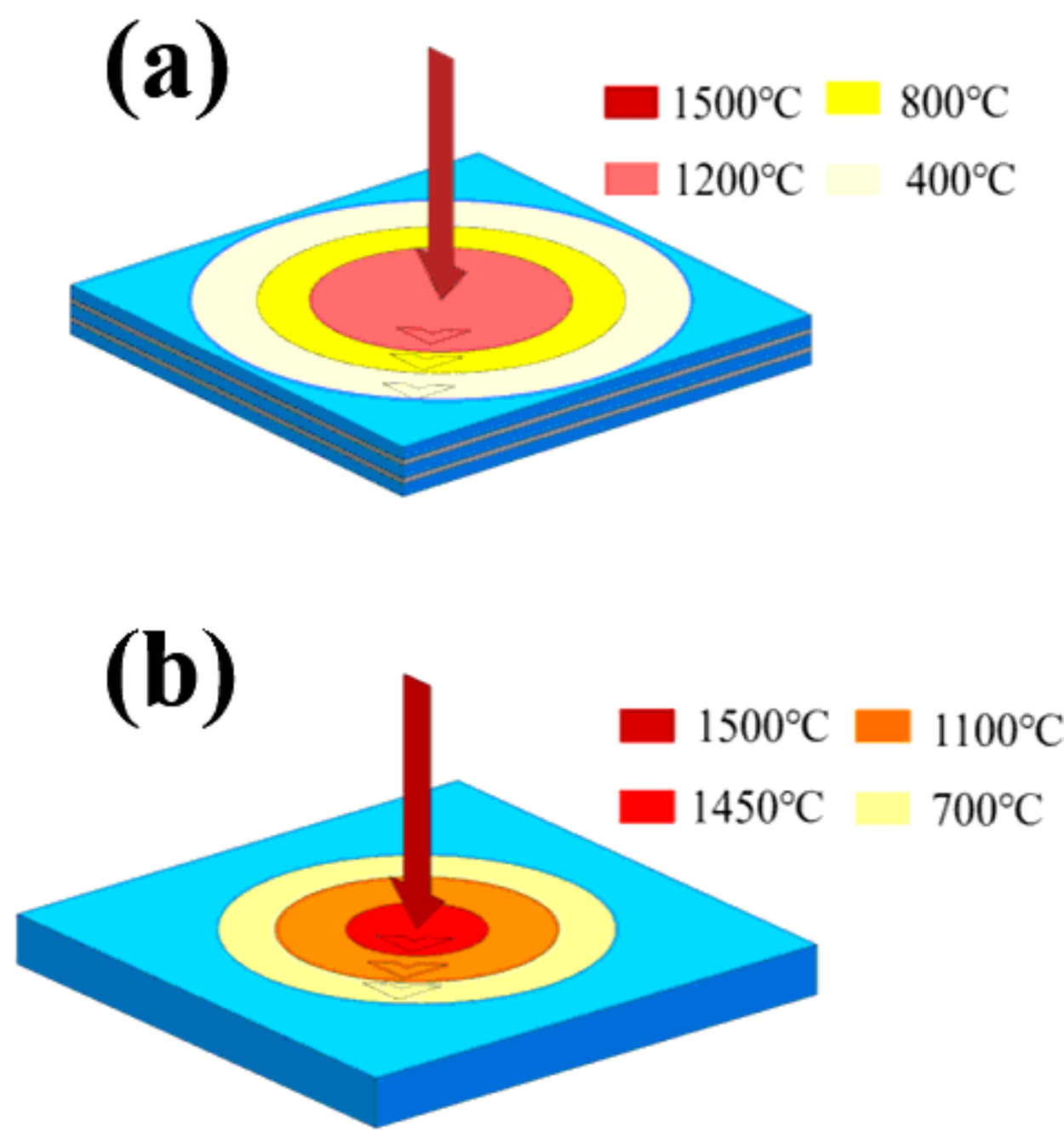

Figure 6

The thermally conductive mechanism of materials: (a) high thermal C/SiC composite (b) C/SiC composite. 

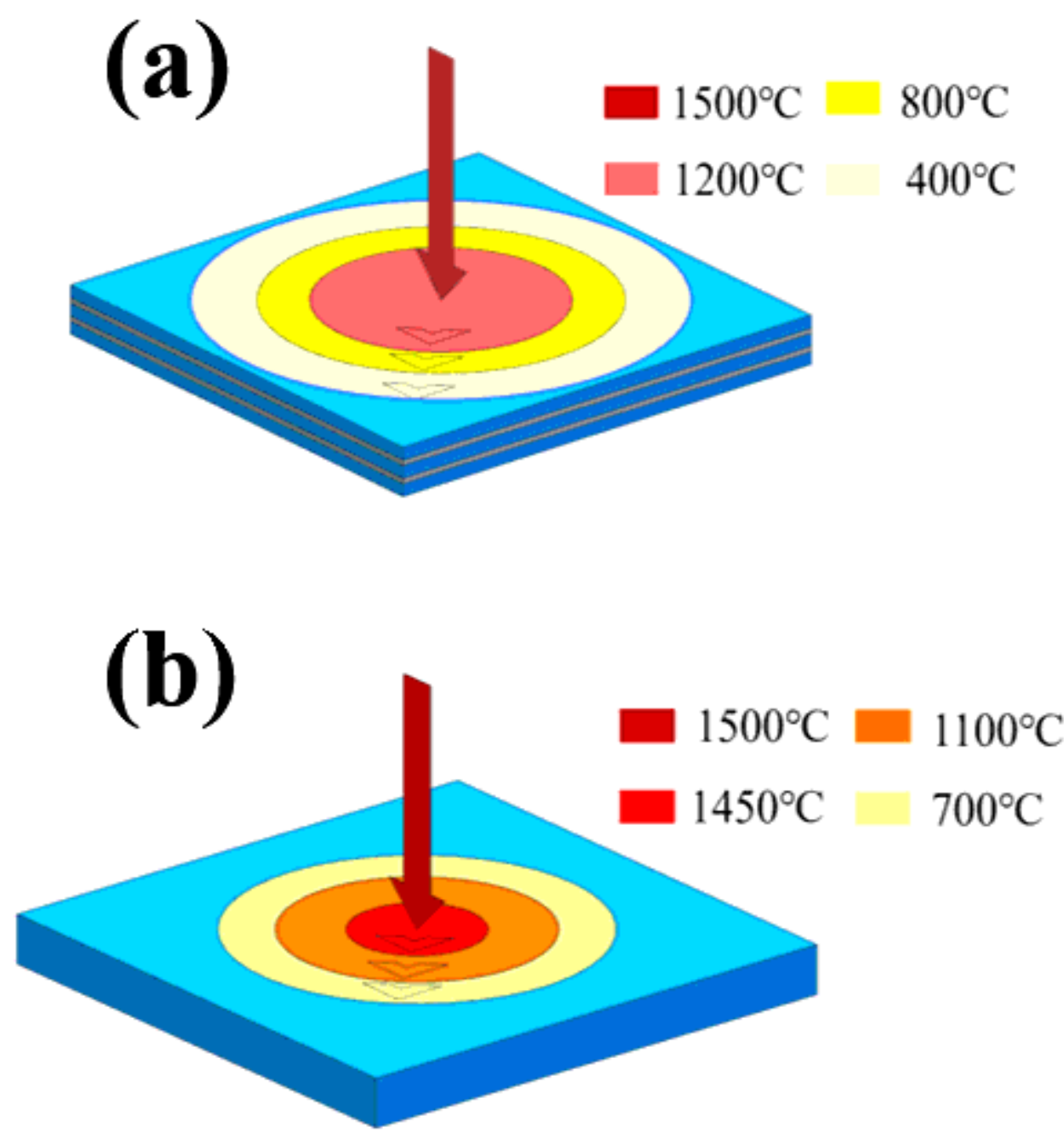

Figure 6

The thermally conductive mechanism of materials: (a) high thermal C/SiC composite (b) C/SiC composite. 


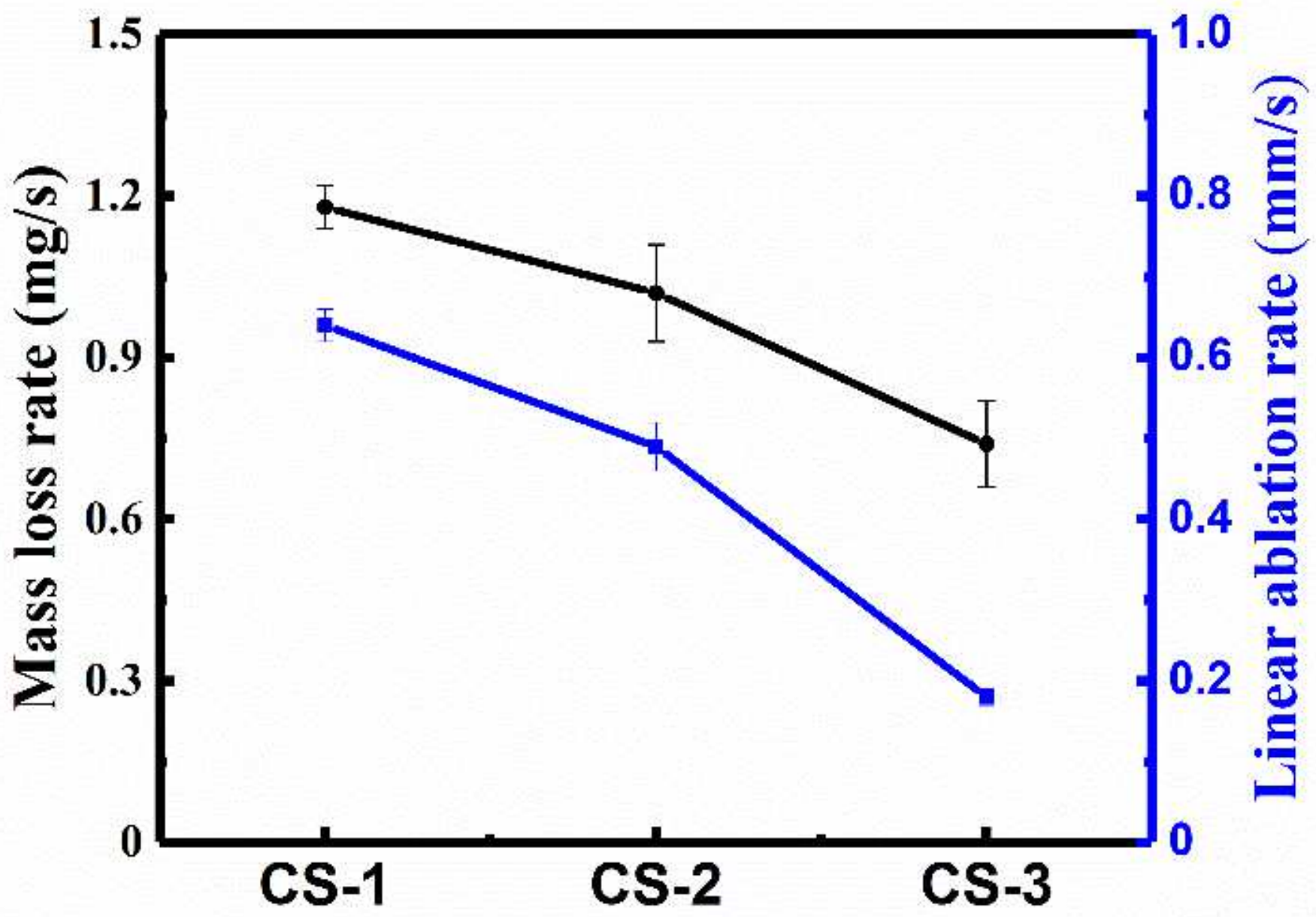

Figure 7

Mass loss rates and linear ablation rates of three materials. 


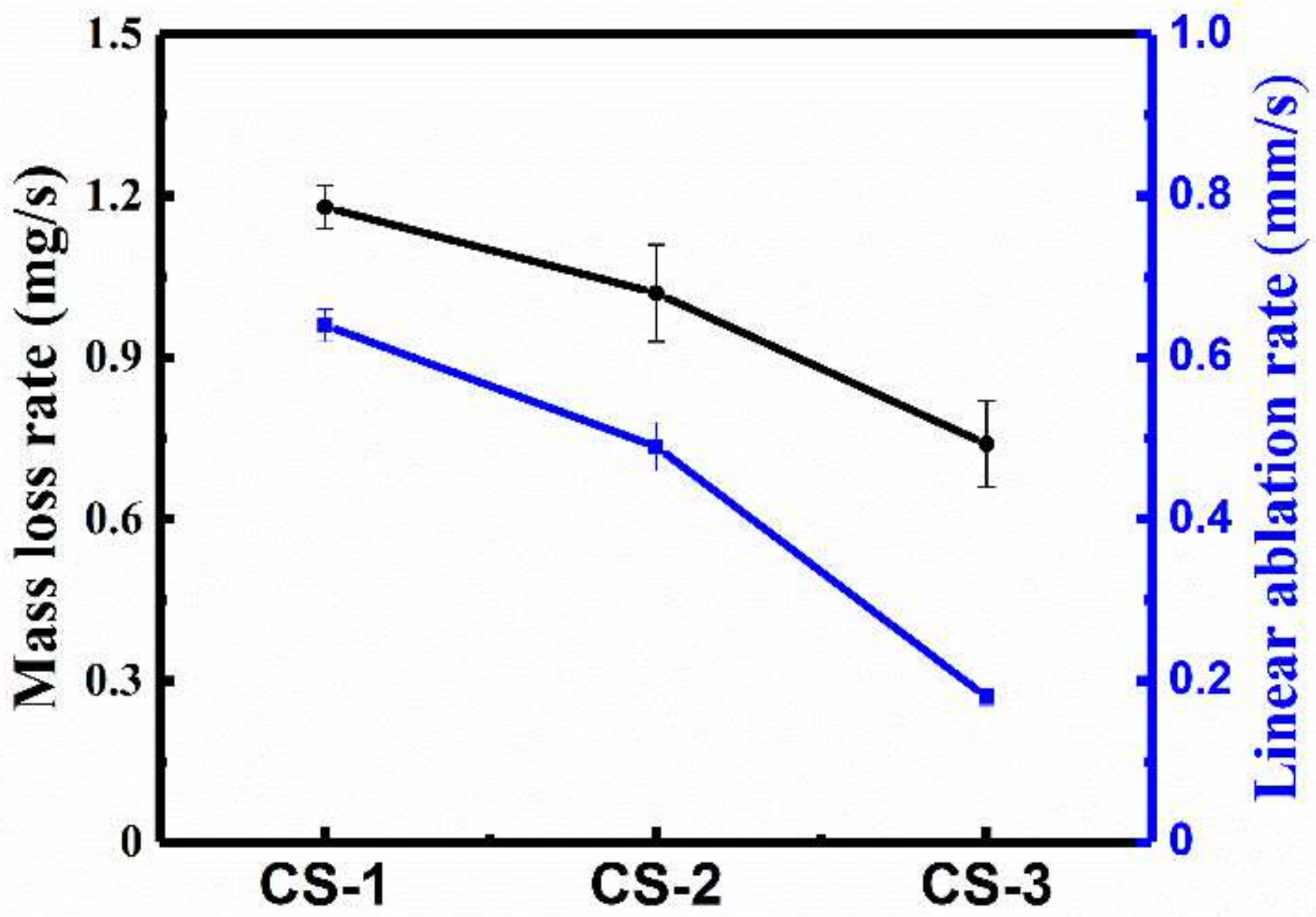

Figure 7

Mass loss rates and linear ablation rates of three materials. 


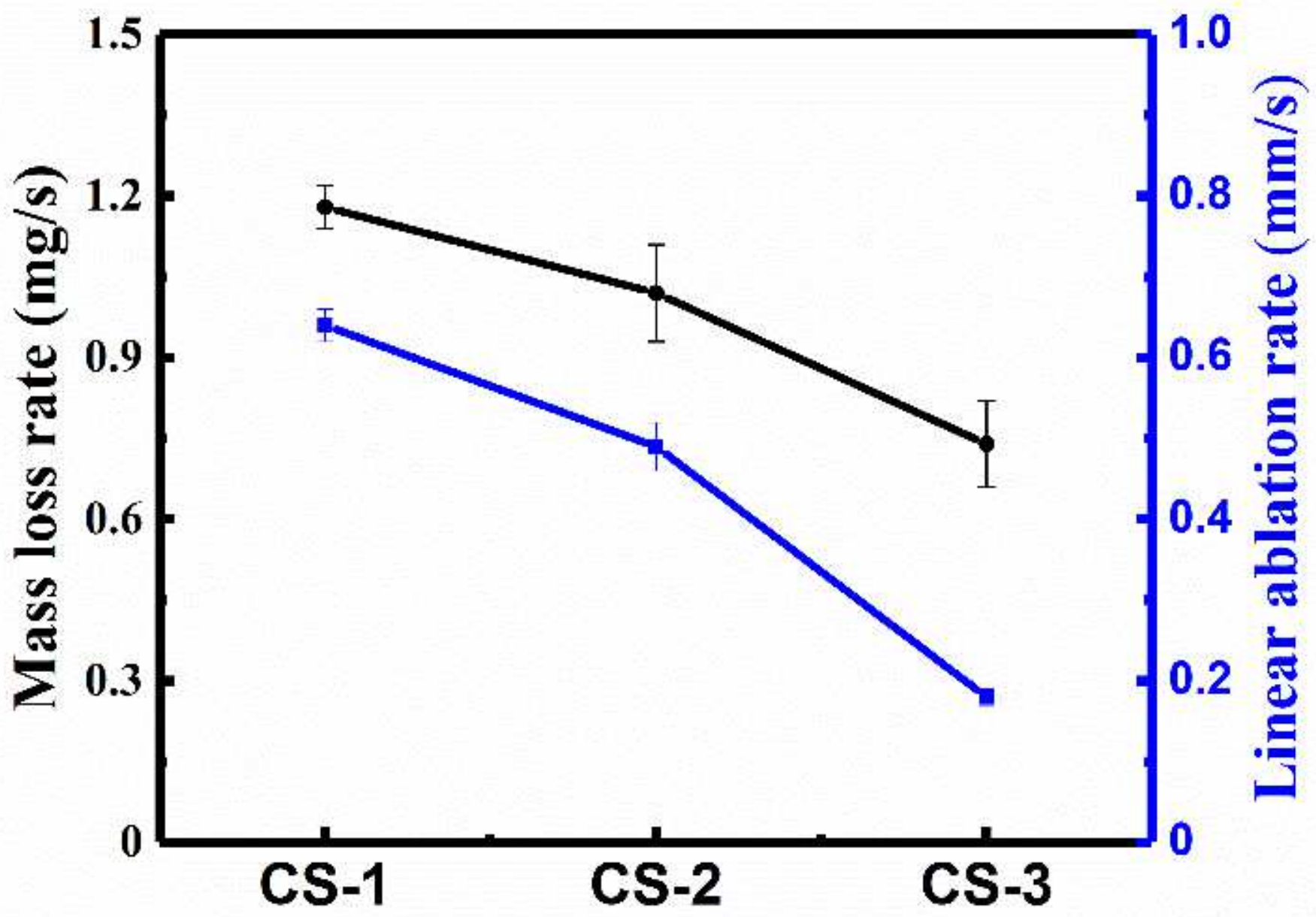

Figure 7

Mass loss rates and linear ablation rates of three materials. 

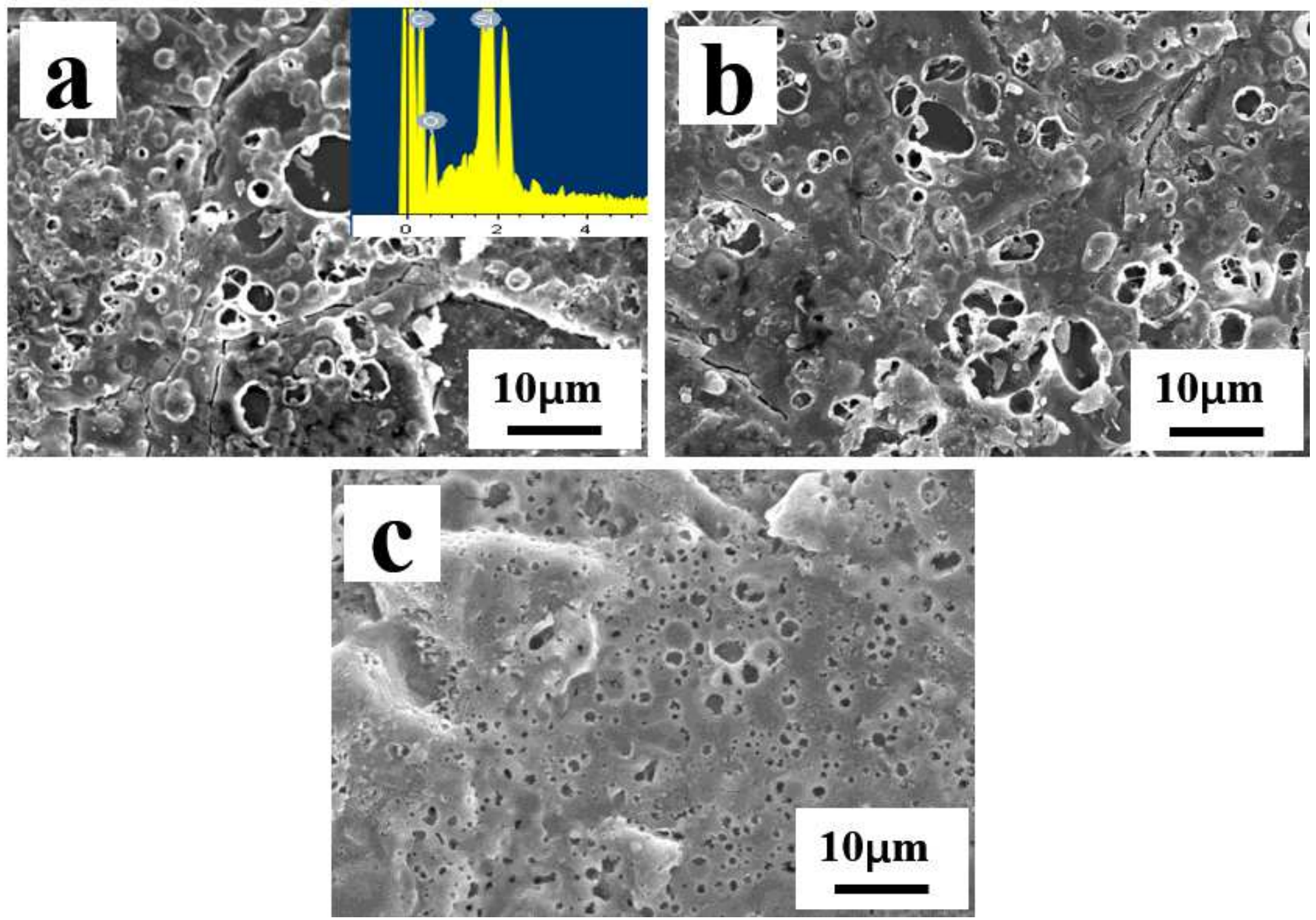

Figure 8

SEM images of the cross section of three materials after ablation at $1500^{\circ} \mathrm{C}$ : (a) CS-1, (b) CS-2 and (c) CS-3. 

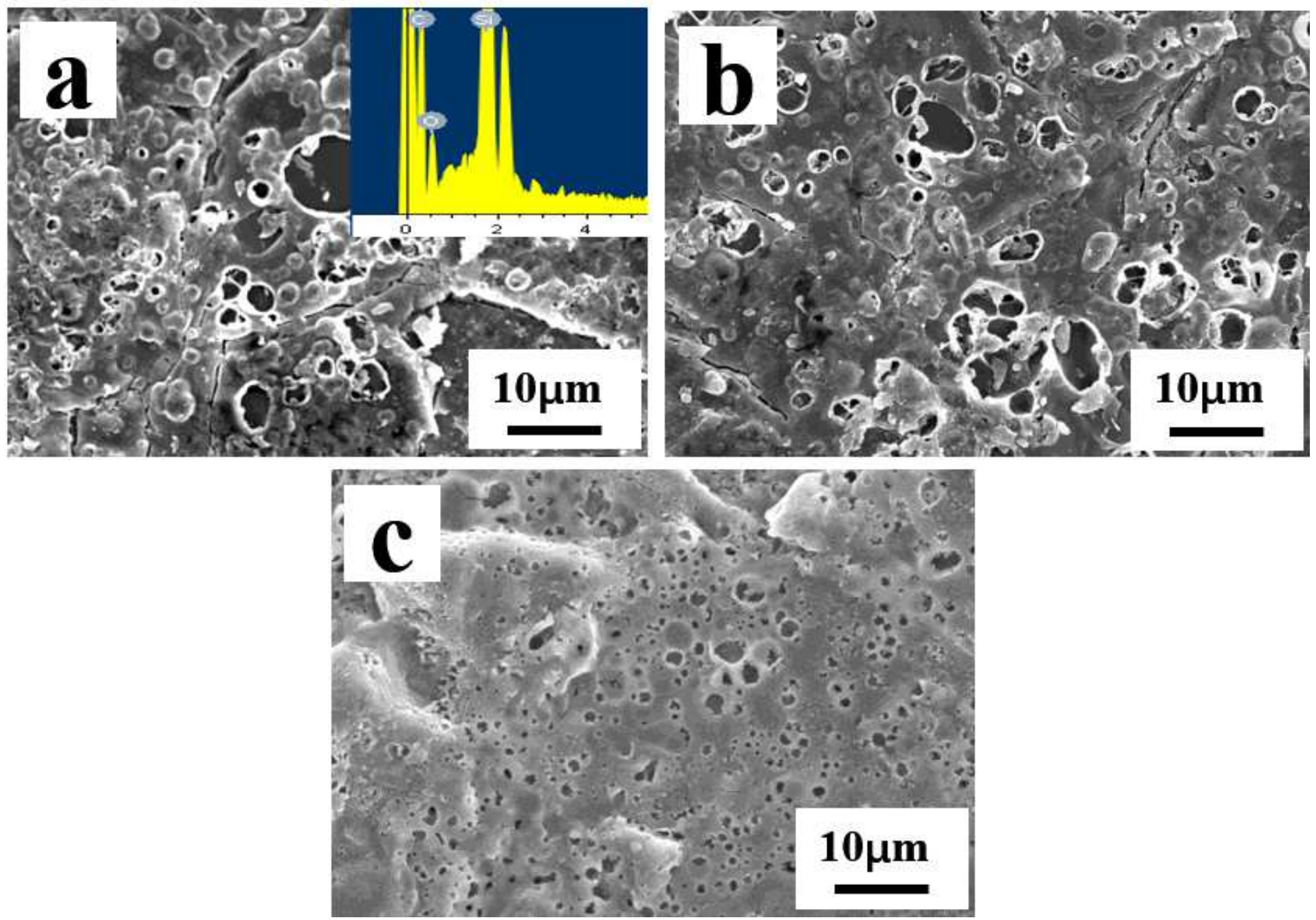

Figure 8

SEM images of the cross section of three materials after ablation at $1500^{\circ} \mathrm{C}$ : (a) CS-1, (b) CS-2 and (c) CS-3. 

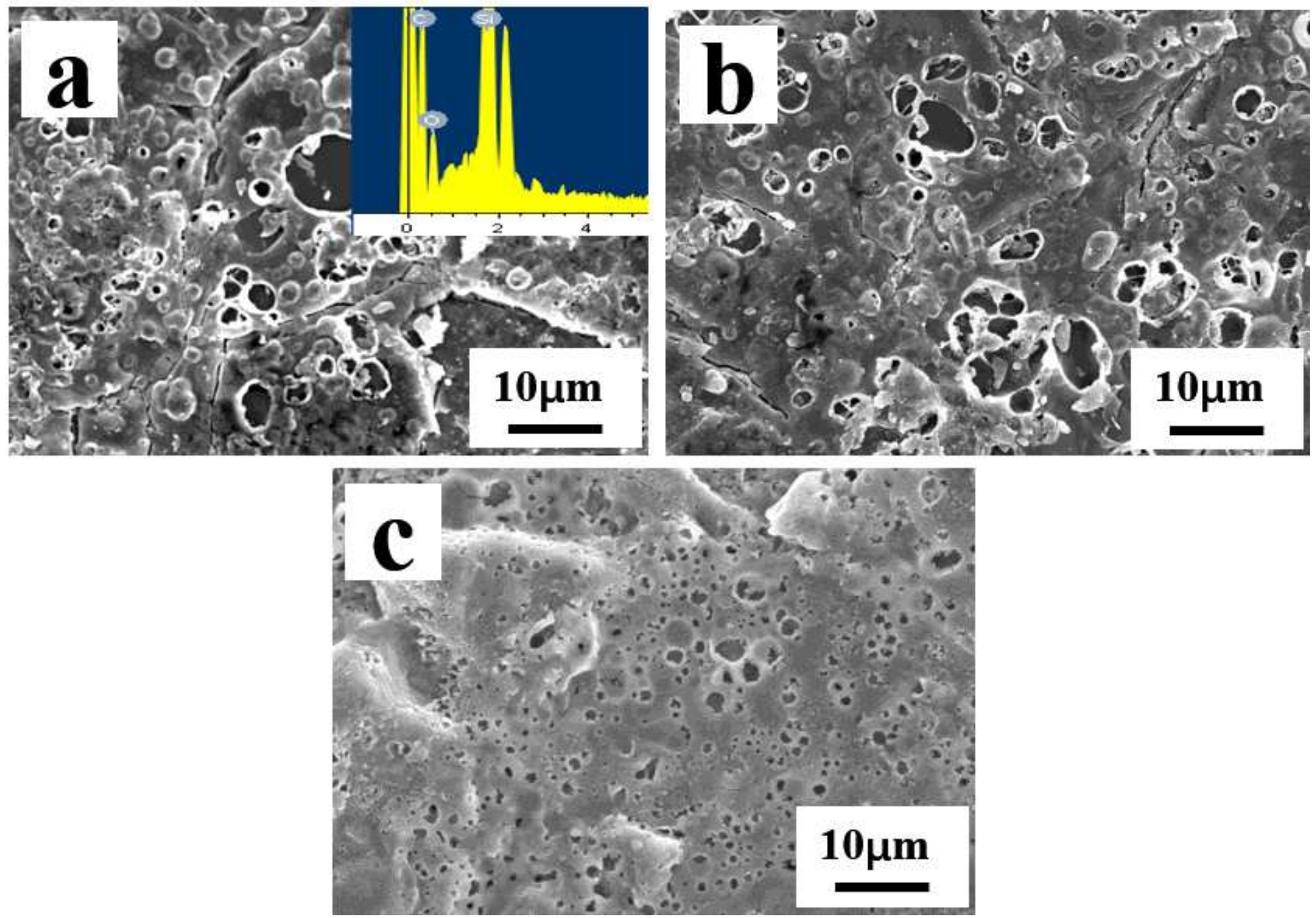

Figure 8

SEM images of the cross section of three materials after ablation at $1500^{\circ} \mathrm{C}$ : (a) CS-1, (b) CS-2 and (c) CS-3. 